\title{
RECENT DEVELOPMENTS ON DISCONTINUOUS PRECIPITATION
}

The discontinuous precipitation (DP) belongs to a group of diffusive solid state phase transformations during which the formation of a new phase is heterogeneous and limited to a migrating reaction front (RF). The use of analytical electron microscopy provided reliable information that there is no differences in the diffusion rate at the stationary grain boundary and moving RF of DP reaction. On the other hand, the use of "in situ" transmission electron microscopy observations indicated the importance of stop- go motion or oscillatory movement of the RF.

During 2004-2016 period more or less 280 papers were published in which the terms "discontinuous precipitation, "cellular precipitation", discontinuous coarsening" appeared either in the abstract or in key-words.

In the present contribution, the research on the DP reaction will be reviewed taking into account new aspects of theories and modelling, new evidences and findings, effect of various factors including third element, external stresses, plastic deformation and GB orientation, occurrence in less known systems and alloys like: superalloys, nitrided Fe-based alloys and Cu-based alloys. Finally, some suggestions for the future research will be formulated.

Keywords: discontinuous precipitation, discontinuous coarsening, grain boundary diffusion

\section{Introduction}

The discontinuous precipitation (DP) is diffusive solid state phase transformation during which a supersaturated solid solution decomposes into a usually lamellar structure of new phase $\beta$ and solute depleted $\alpha$ phase having the same crystal structure as initial phase $\alpha_{o}\left(\alpha_{o} \rightarrow \beta+\alpha\right)$. The formation of new phase is limited to a migrating reaction front (RF). The reaction front separating the transformation products from the parent phase is considered to be a high-angle grain boundary (GB) which serves as a path of rapid diffusion. The name "discontinuous" originates from the discontinuous or very sharp change in the chemical composition as well as crystal orientation between the initial phase and the matrix ( $\alpha$ phase) of the reaction products across the reaction front.

In the advanced stage of ageing discontinuous coarsening (DC) is observed during which a fine lamellar structure formed due to DP is transformed into a coarser one containing the same $\alpha$ and $\beta$ phases $\left[(\beta+\alpha)_{\text {fine }} \rightarrow\left[(\beta+\alpha)_{\text {coarse }}\right]\right.$. If the lamellar microstructure resulting from DP is annealed above or close to the solvus line, the discontinuous dissolution (DD) can takes place by backward migration of the RF with formation of highly inhomogeneous solid solution according to scheme: $\beta+\alpha \rightarrow \alpha \sim$. Fourth type of discontinuous reaction is diffusion-induced grain boundary migration (DIGM) but in this case there is only migrating boundary, no phase transformation takes place, only change in composition occurs for growing grain upon inward or outward diffusion.

All mentioned above reactions were described in details in number of reviews like: Williams and Butler [1], Gust [2] and later by Zieba and Gust [3], Manna, Pabi and Gust [4] and Zieba [5]. Especially, the use of analytical electron microscopy technique and the local concept of DP made possible to remove the previously existing difference concerning calculated diffusivities based on the Cahn and Petermann-Hornbogen model. This in turn, provided reliable information that there is no difference in the diffusion rate at the stationary and migrating GB. On the other hand, the use of "in situ" observation indicated the importance of stop- go motion or oscillatory movement of the RF.

At the end of previous millennium, several papers referring to the velocity and spacing selection during DP reaction were published. Klinger, Brechet and Purdy [6] approached this problem assuming that the growth of $\alpha$ and $\beta$ lamellae must be treated simultaneously. In this respect, mass transport in the $\alpha$ lamella was governed by lateral concentration gradients but in the $\beta$ lamella by a gradient of curvature. Then the simple hypotheses of thermodynamic equilibrium and diffusive flux continuity at the $\beta / \alpha_{o} / \alpha$ junction was sufficient to remove the degeneracy of the problem. The Authors claimed that such treatment provides a selection of spacing and transformation front velocity consist-

\footnotetext{
* INSTITUTE OF METALLURGY AND MATERIALS SCIENCE, POLISH ACADEMY OF SCIENCES, 30-059 CRACOW, REYMONTA STR. 25, POLAND 
ent with the experimental results in the literature. However, there are some questions concerning verification of the model. The expression for a local chemical driving force is valid for the case of dilute or ideal solutions while the model was tested against an Al-22 at.\% Zn alloy which is far away from dilute solution. In principle, the reported value $10^{-10} \mathrm{~cm}^{2} / \mathrm{s}$ as typical for the GB diffusion coefficient does not correspond to the results obtained by Solorzano and Purdy $[7,8]$ even taking that the thickness of a grain boundary is $10^{-9} \mathrm{~m}$. Also, if the point indicated in Fig. 6 is the value of Cahn parameter equal to 2 , such value was not obtained from any microanalytical scans performed across the $\alpha$ lamellae at $428 \mathrm{~K}$ [8]. Other issues associated with DP like influence of jerky motion on the solute concentration profiles across the $\alpha$ lamellae [9], the importance of the solute drag effect at the moving RF [10] were thoroughly discussed by Zieba [11] and conclusions taken are invitation for the further research.

Finally, in the paper by Klinger, Brechet and Purdy [12] dealing with discontinuous homogenization in multilayers, the interesting case was taken into account. It was claimed that the so-called fingering instability can exist at the grain boundary as result of the non-steady state conditions and relatively high thermodynamic driving force. The situation is schematically shown in Fig. 1. Quite similar picture was observed during "in-situ" observation of the DD in the Al-22at.\% Zn alloy (see Figs. 2a-b). This was not exactly the same case because the DD process did not take place at the boundary between two different areas of DP (colonies). However, the areas marked by arrows in Figs. 2a-b correspond quite well with Fig. 1b describing sinusoidal instability. Figure $2 \mathrm{c}$ shows merging two relatively shallow instabilities which is somehow similar to Fig. 1c.

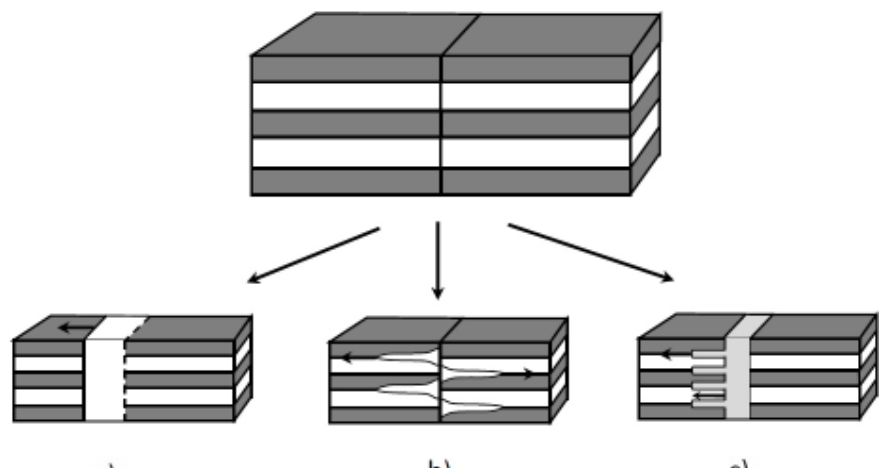

a)

b)

c)

Fig. 1. Three possibilities of discontinuous homogenization of a multilayer containing a moving grain boundary by steady state motion (a), sinusoidal instability (b) and fingering instability (c) of a moving grain boundary. Reproduced with permission from Elsevier Science Ltd., L.M. Klinger, Y.J.M. Brechet, G.R. Purdy, Acta Mater. 1997, 45, 4667-4674, Fig. 1 [12]

What is the progress made during last decade? During 20042016 period more or less 280 papers were published in which the terms "discontinuous precipitation, "cellular precipitation", discontinuous coarsening" appeared either in the abstract or in the key-words. There were no reviews like those of Zieba and Gust [3], Manna, Pabi and Gust [4]. However, chapter by Brechet
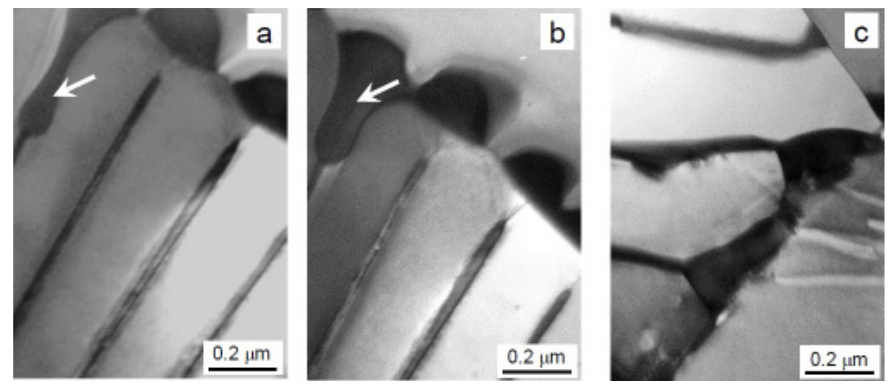

Fig. 2. (a-b) In-situ taken transmission electron microscopy (TEM) micrographs showing two successive stages of dissolution process after discontinuous precipitation in $\mathrm{Al}-22 \mathrm{at} . \% \mathrm{Zn}$ alloy annealed at $570 \mathrm{~K}$ for $5 \mathrm{sec}$ and previously aged at $450 \mathrm{~K}$ for $10 \mathrm{~min}$. (c) the same alloy but annealed at $450 \mathrm{~K}$ for $3 \mathrm{sec}$.

and Hutchinson [13] in the book on solid state physics is worth to mention as it is dealing with many aspects of discontinuous and eutectoid reactions. Also, Aaronson et al. [14] in the monograph "Mechanism of diffusional phase transformations in metals and alloys" dedicated whole chapter to the discontinuous precipitation.

In the following sections, the research on the DP and DC will be reviewed taking into account new aspects of theories and modelling, new evidences and findings, effect of various factors including third element, external stresses, plastic deformation and GB orientation, occurrence in less known systems and alloys like: superalloys, nitrided $\mathrm{Fe}$-based alloys and $\mathrm{Cu}$-based alloys. Finally, some suggestions for the future research will be formulated. The DD reaction will be excluded from the consideration due to limited research results reported and literature and lack of spectacular achievements.

\section{New theories and models}

Lyashenko [15] proposed model of the DP using a set of equations for the (i) mass transfer in the moving interphase boundary, (ii) balance of the entropy fluxes at the phase transformation front, and (iii) maximum rate of the free energy release. The use of the principle of maximum rate of free energy release and balance of entropy fluxes allowed an independent determination of the main parameters, including the interlamellar distance, the maximum velocity of the phase transformation front, and the concentration jump at this boundary.

As a consequence, the following equation was obtained:

$$
k L\left(c_{o}-c^{\frac{\alpha}{\beta}}\right)^{2}=8 \gamma\left\{\begin{array}{l}
\frac{\Delta z}{L} s c h^{2}\left(\frac{\Delta z}{L}\right)+ \\
-\frac{2 c^{\alpha / \beta}-c_{o}-c^{\beta}}{c^{\beta}-c_{o}} \operatorname{th}\left(\frac{\Delta z}{L}\right)
\end{array}\right\}^{-1}
$$

with $k=\left.g^{\prime \prime}\right|_{c} ^{\alpha / \beta}>0$ and $L=\sqrt{s \tilde{D} h / v}$

where $k$ - the Gibbs potential curvature in the $\alpha$ lamella at the $\alpha / \beta$ junction, $c^{\alpha / \beta}$ - the equilibrium concentration in the a phase 
lamella at the $\alpha / \beta$ junction, $c^{\beta}$ - the equilibrium concentration in the $\beta$ lamella, $c_{o}$ - the concentration of the alloy, $\Delta z$ - half of the $\alpha$ lamella thickness, $s$ - the segregation coefficient, $h$ - the width of the GB, $v$ - the velocity of the GB, $\widetilde{D}$ - the interdiffusion coefficient at the GB. Note that $L$ is related to Cahns parameter $C$ by the equation:

$$
L=\frac{2 \Delta z}{\sqrt{C}}
$$

The basic equation (1) relates $\Delta z$ and $L$ and makes possible to apply the principle of maximum rate of free energy release in order to find the optimal $\Delta z$ using condition:

$$
\frac{d \varphi}{d(\Delta z)}=0
$$

The model was verified (assuming the quadratic equation for Gibbs energy and a relatively high mobility of the boundary) for the only one set of data in Ni-1.4at.\% In. Therefore, in order to prove that the model is working properly, the test should be performed for whole set of data reported in the paper by Bögel and Gust [16]. Additionally, the values of $C$ parameters determined directly based on the microanalytical scans across the $\alpha$ lamella as those of Alexander [17] are more relevant for this purpose.

Another test was performed for $\mathrm{Pb}-\mathrm{Sn}$ system but using thermodynamic description based on the regular solution model. Lyashenko [15] emphasized a good correlation between the calculated and experimental parameters of DP reaction. However, the calculated concentration change across the $\alpha$ lamella for the $\mathrm{Pb}-15$ at.\% $\mathrm{Sn}$ alloy corresponds to extremely thin lamella $(50 \mathrm{~nm})$ which is highly unrealistic because the same Author provides $120 \mathrm{~nm}$ as a typical value of the interlamellar distance.

Supplementary paper delivered by Lyashenko et al. [18] introduced the model of retardation process of the grain-boundary motion by the segregated atoms during DP reaction. On the basis of the proposed model, they calculated the concentration profiles inside the GB along a direction of its motion, the surface energy inside the GB, the coefficient of segregation depending on the GB motion velocity. Within the scope of the model approximations, dependencies of the Gibbs energy dissipation rate caused by atoms segregation at the GBs on GB motion velocity are calculated. As shown, in a certain interval of velocities of the GB motion, the energy-dissipation rate caused by atoms segregation at the GBs can influence a release of Gibbs energy.

Several papers also appeared dedicated to the modelling the occurrence of DP. Robson [19] presented model predicting competition between discontinuous and continuous mode of precipitation. The model applied for the $\mathrm{Mg}$-Al system showed that the formation of continuous precipitates inhibits the DP by reducing the supersaturation, which was found to have much stronger effect than boundary pinning. It was demonstrated that once continuous precipitation becomes established, the DP is effectively suppressed. The formation of discontinuous precipitates only strongly suppressed continuous precipitation when a sufficient volume fraction of DP occurs which substantially reduces the free volume available for the transformation. For the conditions where discontinuous and continuous precipitation occur simultaneously, the reduction in supersaturation caused by the continuous precipitation was predicted to lead to an increase in the interlamellar spacing to maintain an equal growth velocity in both $\alpha$ and $\beta$ lamellae.

Other approach is presented Amirouche and Plapp [20, 21]. They developed a phase field model for the DP reaction by modifying existing solution for the solidification. They used so called the multi-phase-field approach, in which each phase $\left(\alpha_{o}\right.$, $\alpha, \beta)$ was described by one phase field and applied it for only isothermal growth in a binary alloy. Moreover, one assumed that the changes of bulk diffusivity $\left(D_{v}\right)$ were independent of grain boundary diffusivity $\left(D_{b}\right)$ and mobility changes.

Figures 3a-c show how the lamellae morphology is influenced by the changes of $D_{v}$. A characteristic flattening of the tip of the solute-rich lamella is observed if the bulk diffusion decreases. Tis is accompanied by the decrease of growth velocity which could force initially the steady-state morphology (Fig. 3d) to recede (Fig. 3e). Note, that colour scale in Fig. 3 reflects the concentration field ahead of the solute-rich lamella. The use of the phase field model by Amirouche and Plapp [20] revealed that: (i) for given growth conditions and composition, steady-state solutions exist for a range of interlamellar spacing, (ii) the minimum spacing is given by a limit point beyond which no steady-state solution exists anymore; (iii) an oscillatory instability occurs for large interlamellar spacing, which leads to a non-constant growth velocity; and (iv) the breakdown of local equilibrium, an effect analogous to a solute trapping in the solidification, cannot be neglected in the DP.

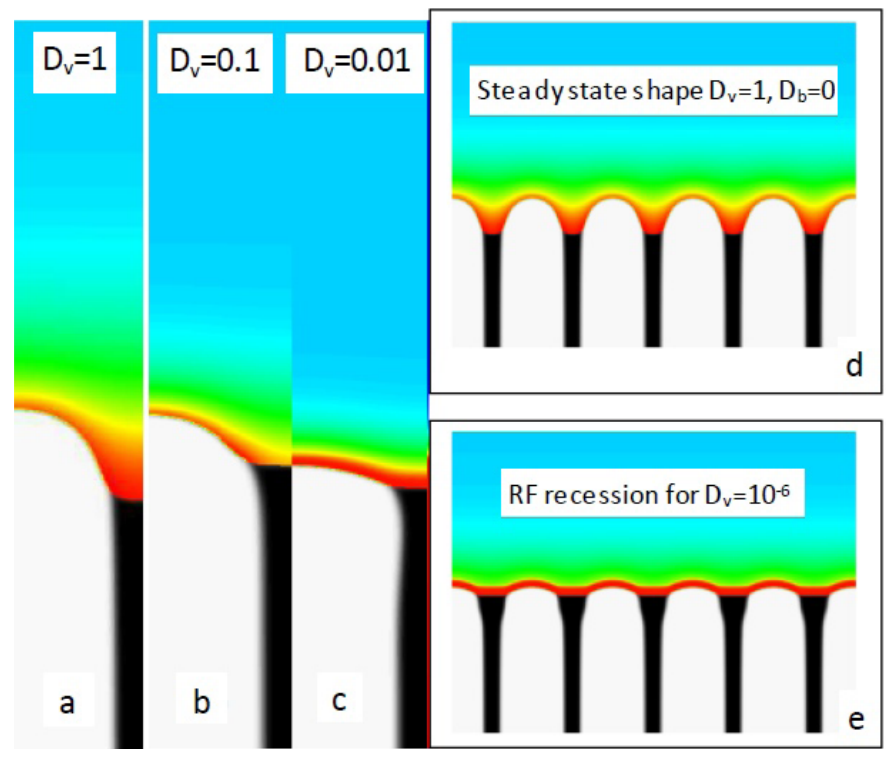

Fig. 3. Effect of bulk diffusion on $\beta$ lamellae morphology (white colour). (a) $D_{v}=1, D_{b}=0$; (b) $D_{v}=0.1, D_{b}=0$; (c) $D_{v}=0.01, D_{b}=0$ for $L / d_{o}=$ 50.91, $D=0.8$; (d) steady state shape of the RF for $D_{v}=1, D_{b}=0$; (e) RF recession for $D_{v}=10^{-6}$. $L$ - lamellar spacing, $D$-supersaturation, $d_{o}$ - capillarity length. Reprinted with permission from Trans Tech Publications, L. Amirouche, M. Plapp: Solid State Phenom. 2011, 172174, 549-554, Fig. 5 [21] 
Further research made by Amirouche and Plapp [21] showed that that the growth of pre-existing nuclei at the GB did not lead to the steady-state growth if the GB diffusion was the only active transport process. Instead, a lateral growth of the nuclei along GBs was observed to take place. Nuclei could develop into lamellae with characteristic bowing of the RF for the bulk diffusion control process (Fig. 4). The numbers inserted in each picture indicate the time sequence during simulation that: $t=n \times$ ifre $\times \Delta t$, where $\Delta t=0.02$ (in units of the phase-field relaxation time), and ifreq denotes the frequency of picture "emission" and varies from one run to the other (ifreq $=2 \times 10^{4}$ generally). The main conclusion coming from the research of Amirouche and Plapp [21] was that a formation of lamellar cells, the bowing of the RF as well as the migration of the RF could be reproduced by the phase field method and that the bulk diffusion is important for the formation of solute rich precipitates and the initiation of the DP reaction. On the other hand, the steady-state growth rates depend generally on both bulk and surface diffusivities, as well as on the GB mobility.

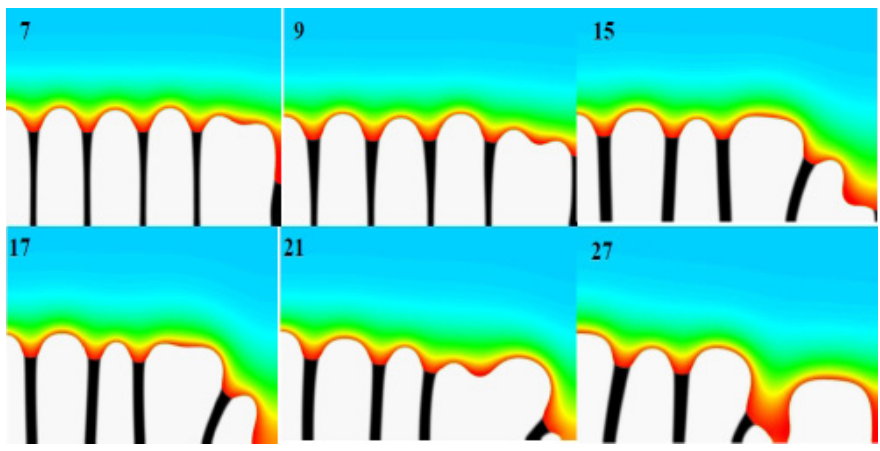

Fig. 4. Formation of lamellar structure, motion and shape changes of the reaction front for DP reaction controlled by bulk diffusion: $D_{v}=1$ and $D_{b}=0$. Numbers in left upper corner indicate the time sequence during the run in phase field. Note that black colour is for the solute-depleted $\alpha$ lamellae. Reprinted with permission from Trans Tech Publications, L. Amirouche, M. Plapp: Solid State Phenom. 2011, 172-174, 549-554, Fig. 4 [21]

One should note that all the considerations of Amirouche and Plapp referred to solute-rich lamella, which is white in all the simulations and shows larger thickness than solute-depleted lamella (black colour). They also did not refer their results to any specific alloy system in which the DP reaction occurs. Especially, concentration field ahead of the RF was not confirmed by the measurements of solute concentration profiles (see for example: Zieba, Gust [3]). Also, the data on GB diffusivity reported by Gust [2] are 4-5 orders of magnitude larger than those for the bulk diffusion. In such case, even if there is some bulk diffusion preceding formation of a solute rich lamellae, the resulting concentration field should disappear during growth of regular colonies of DP precipitates.

Quite recently, Duong and Arroyave [22] have applied so-called multiscale modelling for the DP in U-Nb alloy which included first-principles calculations and CALPHAD to assess self-consistent thermodynamic description of $\mathrm{U}-\mathrm{Nb}$ system.
Then, atomic mobility and diffusivity was determined again using CALPHAD via DICTRA package. This in a consequence, made possible phase field simulations in order to reproduce the lamellar structure resulting from DP reaction (Fig. 5). This first result shows the potential of such treatment but much deeper analysis has to be made in order to obtain better agreement. It is not also clear which alloy was taken for the comparison U-13at.\% $\mathrm{Nb}$ or $\mathrm{U}-17$ at.\% $\mathrm{Nb}$. One should also note that Hackenberg [23] observed for the first time DC reaction for the U-13at.\% $\mathrm{Nb}$ alloy for ageing at 73,723 and $773 \mathrm{~K}$. For $623 \mathrm{~K}$ this reaction is expected to begin after 2 years.
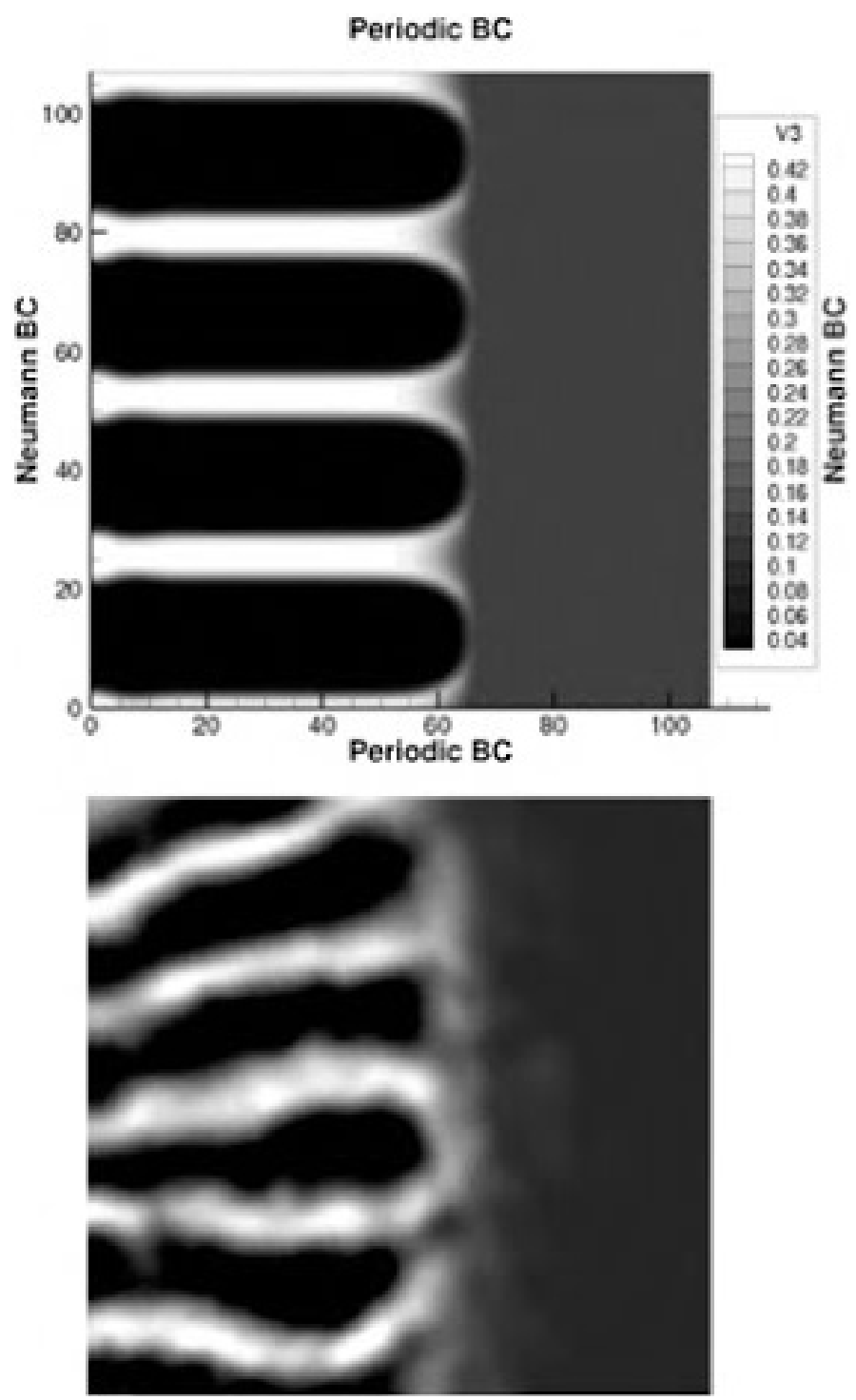

Fig. 5. Experimentally observed DP lamellae in U-Nb alloy in comparison with simulated microstructure at $773 \mathrm{~K}$ for $1490 \mathrm{~s}$. Reprinted with permission from John Wiley and Sons, T. Duong, R. Arroyave: in 'The TMS Middle East - Mediterranean Materials Congress on Energy and Infrastructure Systems (MEMA 2015)', (ed. I. Karaman, R. Arroyave, E. Masad), 481-490; 11-14 January 2015, Doha, Qatar, The Minerals, Metals \& Materials Society (TMS), Fig. 4b [22] 


\section{Discontinuous precipitation related phenomena}

\subsection{Discontinuous precipitation with formation of liquid phase}

In principle, we should address this type of reaction to so-called liquid film migration (LFM). However, in some cases initial slab of liquid film is transformed into the lamellar structure typical for the DP reaction. Such kind of reaction was described by Kucharenko [24] in the supersaturated Bi-Sb alloys and also quite recently observed by Gupta and co-workers $[25,26]$ in the $\mathrm{Cu}-9.5$ at.\% In and $\mathrm{Cu}-7.5$ at.\% Sn alloys during overheating of the supersaturated solid solution $\alpha_{o}$ above the equilibrium solidus temperature. In such circumstances, a layer of liquid forms at the GB which makes this process adequate to the LFM. Such behaviour was observed rather for higher temperatures. However, at lower temperatures (in some cases even below equilibrium solvus), the diffusion of solute atoms which occurs within the liquid layer, leads to development of the structure consisted of alternate solute-depleted (alpha) and liquid phases (Fig. 6a). The nucleation of the liquid droplets occurred at the GB as two hemispherical caps abutted at the original GB positions (Fig. 6b)
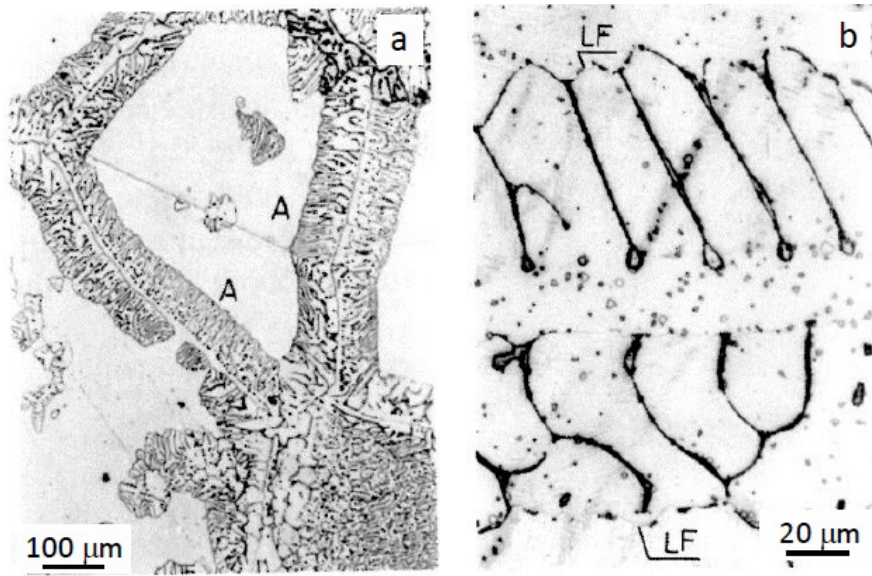

Fig. 6. (a) LM micrograph of Cu-9.5at.\% In, annealed $10 \mathrm{~s}$ at $1022 \mathrm{~K}$, (b) LM micrograph of Cu-7.5at.\% Sn, $18 \mathrm{~s}$ at $1081 \mathrm{~K}$. Reprinted with permission from Carl Hanser Verlag GmbH \&Co. KG, Muenchen, S.P. Gupta, S.K. Goutam, R.S. Babu: Z Metallkd. 2003, 94, 442-448, Fig. 8 and $11[25]$

Babu and Gupta [26] pointed also out that in the $\mathrm{Cu}-7.5 \mathrm{at} . \%$ Sn alloy with an overheating of up to $22 \mathrm{~K}$ the measured growth rate was two to three orders of magnitude higher than that observed during the DP in the solid state in the Cu-based alloys. The interlamellar spacing was also an order of magnitude higher. However, the growth rate increased with increasing transformation temperature while interlamellar spacing decreased. Babu and Gupta [26] performed also the analytical scans across liquid lamellae. However, due to limited spatial resolution of conventional electron energy probe microanalyser such kind of measurements should be done carefully once again using analytical electron microscopy.

\subsection{Discontinuous spinodal decomposition}

Theoretical fundamentals for a discontinuous spinodal decomposition (SD) were provided by Ramanarayan and Abinandanan [27, 28]. Initially, they developed phase field model to study the GB effect on the spinodal decomposition in systems in which the atomic mobility at the GB is the same as that in the grain interior. Later on, the model was adapted to the case of so-called enhanced atomic mobility at the GB. Figure 7 shows microstructure evolution for the different values of $M_{t}, L$ and $t$. Here, $M_{t}$ is the enhanced atomic mobility in the plane of $\mathrm{GB}, L$ is the relaxation coefficient and $t$ - time. $M_{t}$ is related to $M_{g}$ - the effective atomic mobility at the GB, and hence, to the GB diffusivity, which is experimentally measurable. Similarly, $L$ is related to another experimental quantity, the GB mobility $L_{g}$, which determines the rate of GB migration under a driving force, such as GB curvature. (a)

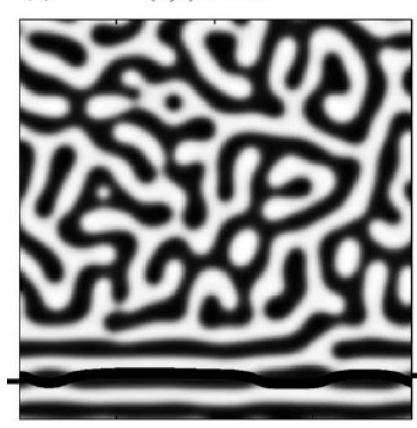

(c)

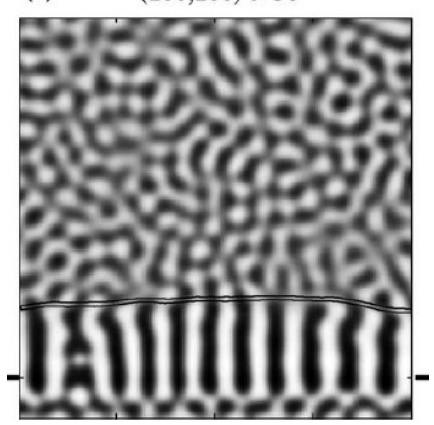

(b)

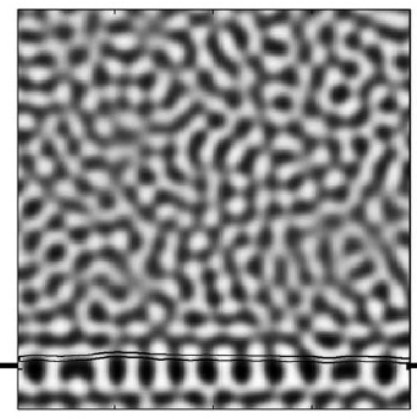

(d)
Fig. 7. Microstructural evolution in four different systems with different combinations of (Mt, L) indicated at the top of each figure. Original location of GB is shown by short, horizontal lines on each side. The current location of this boundary is indicated using a double line. In (a) and (b), the GB is stationary, while in (c) and (d), it has migrated considerably. Reprinted with permission from Elsevier Science Ltd, H. Ramanarayan, T.A. Abinandanan: Acta Mater. 2004, 52, 921-930, Fig. 1 [28]

For the $M_{t}=0$ there is no enhancement in the atomic mobility at the GB (Fig. 7a). Larger value of $M_{t}=50$ leads to some decomposition at the GB, while the GB is being enriched with $A$ (in black) species (Fig. 7b). As soon as both $M_{t}$ and $L$ exceed a critical value a discontinuous microstructure consisting of alternating A-rich and B-rich lamellae starts to grow perpendicular to the front. For the case shown in Fig. $7 \mathrm{c}$ the migration rate of 
the RF it is slow enough to allow the grain interiors to undergo normal SD; thus, the system exhibits a mixture of normal SD and discontinuous SD microstructures. For the very large $M_{t}$ and $L$ (Fig. 7d), the front movement is so fast that no SD can take place in the grain interior. Therefore, such microstructures as those growing from the GB in Fig. 7c and 7d were called by Ramanarayan and Abinandanan [28] as discontinuous SD microstructure. The main differences between classical DP reaction and discontinuous SD is that in the DP one of the lamella must be the precipitate phase, whose composition is significantly different from that of the matrix. In the discontinuous SD, the lamellae are created due to a composition wave of relatively large amplitude but sumultaneously coherent interfaces exists between the A-rich and B-rich lamellae.

The discontinuous SD may appear in the systems where DP reaction and normal spinodal microstructure within the grains coexist, for example $\mathrm{Cu}-\mathrm{Ni}-\mathrm{Fe}$ [29] and $\mathrm{Cu}-\mathrm{Ni}-\mathrm{Sn}$ [30]. The experimental evidence of the discontinuous SD was delivered by Gorsee at al. [31]. They performed ageing of Pb0.36Ge0.64Te alloy and observed (Fig. 8a) that the supersaturated parent phase $(\mathrm{Pb}, \mathrm{Ge}) \mathrm{Te}$ decomposes at the migrating $\mathrm{RF}$ into regular aggregates of alternating black- $\mathrm{PbTe}(\mathrm{Pb})$ and white- $\mathrm{GeTe}(\mathrm{Pb})$ phases with a constant lamellar spacing. The interlamellar spacing increased from $30 \mathrm{~nm}$ at $473 \mathrm{~K}$ to about $200 \mathrm{~nm}$ at $773 \mathrm{~K}$.
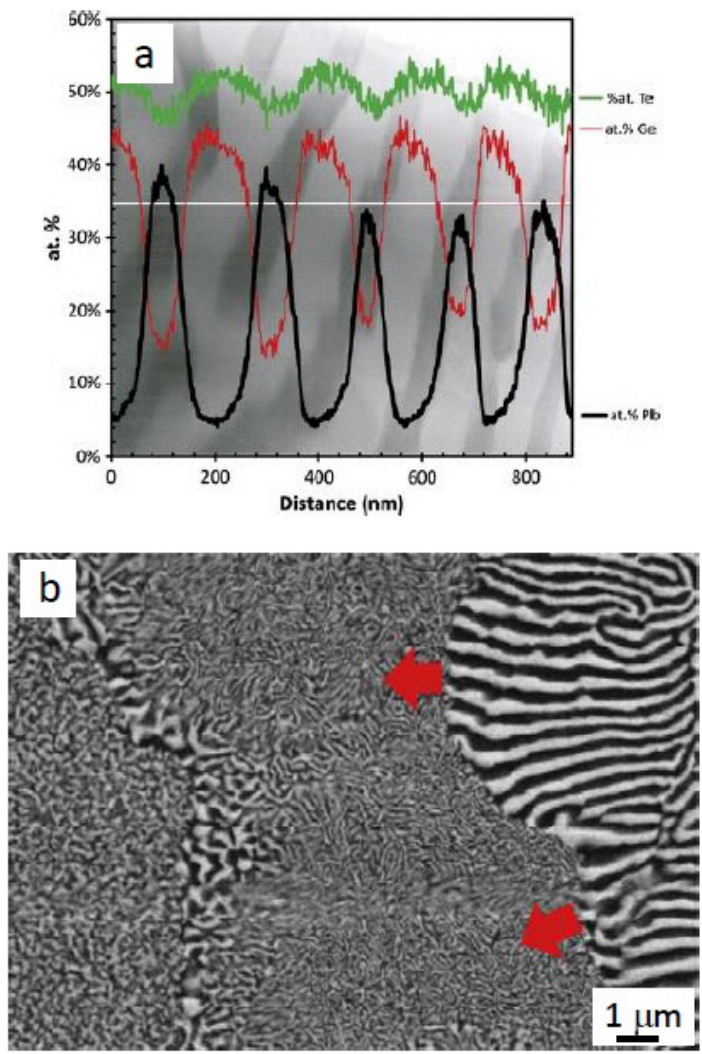

Fig. 8. (a) The lamellar microstructure of $\mathrm{Pb}_{0.36} \mathrm{Ge}_{0.64} \mathrm{Te}$ aged at 673 $\mathrm{K}$ with corresponding EDX line scan across the white solid line. (b) TEM image of the microstructural evolution of the Pb0.36Ge0.64Te alloy during over aging at $773 \mathrm{~K}(\mathrm{PbTe}(\mathrm{Ge})$ in black and $\mathrm{GeTe}(\mathrm{Pb})$ in white). Reprinted with permission from Elsevier Science Ltd, S. Gorsse, P. Bellanger, Y. Brechet, E. Sellier, A. Umarji, U. Ail, R. Decourt: Acta Mater. 2011, 59, 7425-7437, Fig. 5 and middle image of Fig. 6 [31]
The results of an energy dispersive X-ray spectroscopy (EDX) scan (Fig. 8a) clearly revealed that the reaction products are far from equilibrium. Therefore, the discontinuous coarsening is observed after longer time of annealing (Fig. 8b).

The main difference from the classical DP reaction results from the fact that the examined by Gorsse [31] the initial $(\mathrm{Pb}, \mathrm{Ge}) \mathrm{Te}$ solid solution was transformed into a $\mathrm{Pb}$-rich and a Ge-rich phase but having the same crystallographic structure. Moreover, the interlamellar spacing is much finer than that commonly observed during DP reaction (>100 nm). The concentration profiles are likely to be sinusoidal (Fig. 8a) and well located within miscibility gap while in the DP reaction the solute rich lamellae are of equilibrium concentration. Comparing the profile in Fig. 8a with that obtained by He et al. [32] in similar studies (Fig. 9) one can notice the different shape of $\mathrm{Pb}, \mathrm{Te}$ and $\mathrm{S}$ profiles all the spectra show tendency to decrease in the $\mathrm{D}$ area (Fig. 9b). One should note that $\mathrm{He}$ (2010) examined $\mathrm{PbTe}_{0.7} \mathrm{~S}_{0.3}$ which decomposed into $\mathrm{PbTe}$ and $\mathrm{PbS}$.
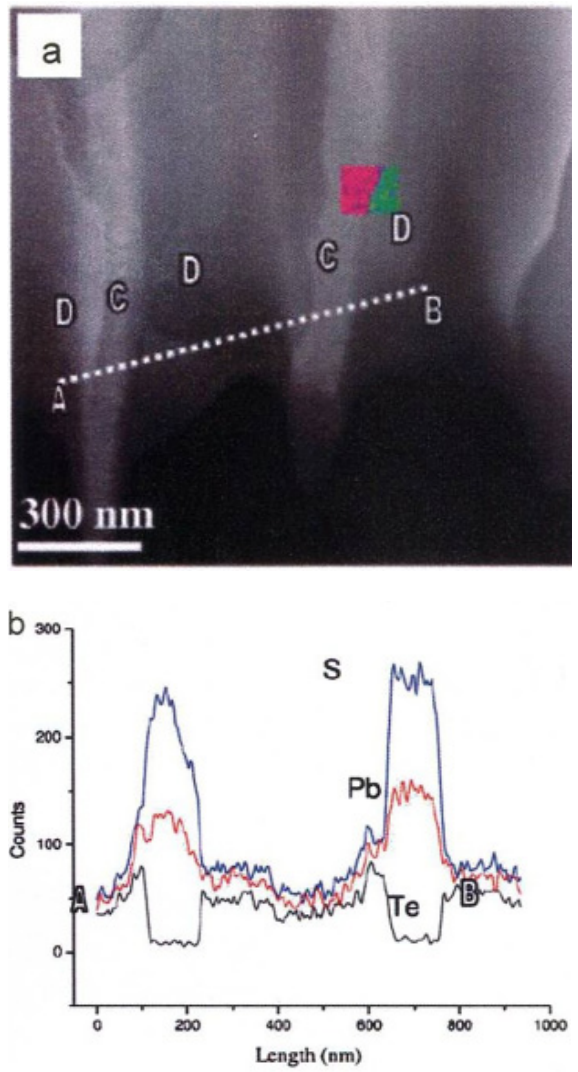

Fig. 9. a) Scanning transmission electron microscopy (STEM) image showing regions of $\mathrm{PbS}$ (labeled $\mathrm{C}$ ) and $\mathrm{PbTe}$ (labeled $\mathrm{D}$ ) of the PbTe0.7S0.3 aged at $773 \mathrm{~K}$ for $8 \mathrm{~h}, \mathrm{~b}$ ) EDX line scan from A to B in (a). Reprinted with permission from Wiley-VCH Verlag $\mathrm{GmbH} \& \mathrm{Co}$, J. He, S.N. Girard, M.G. Kanatzidis, V.P. Dravid: Adv. Funct. Mater. 2010, 20, 764-772, Fig. 2c [32]

\section{Experimental verification-analytical approach}

The rapid development of the new analytical techniques and diagnostic tools makes possible to obtain a very detailed information about nanostructure, chemistry, crystallography of the 
DP reaction. Especially, the techniques of the energy dispersive $\mathrm{X}$-ray spectroscopy, an energy electron loss spectroscopy and atom probe tomography have a large potential to contribute to the better understanding the DP reactions.

Lopez et al. [33] measured for the first time the concentration profile along the RF, i.e. a migrating grain boundary of the DP reaction in the $\mathrm{Cu}-4.5$ at.\% In alloy. Comparison of this profile to that taken across the $\alpha$ lamella at some distance from the RF (Fig. 10) clearly indicated that the segregation factor $s$, defined as the ratio between the concentration at the RF and the concentration in the solute-depleted lamella, is not the same in the entire lamella.
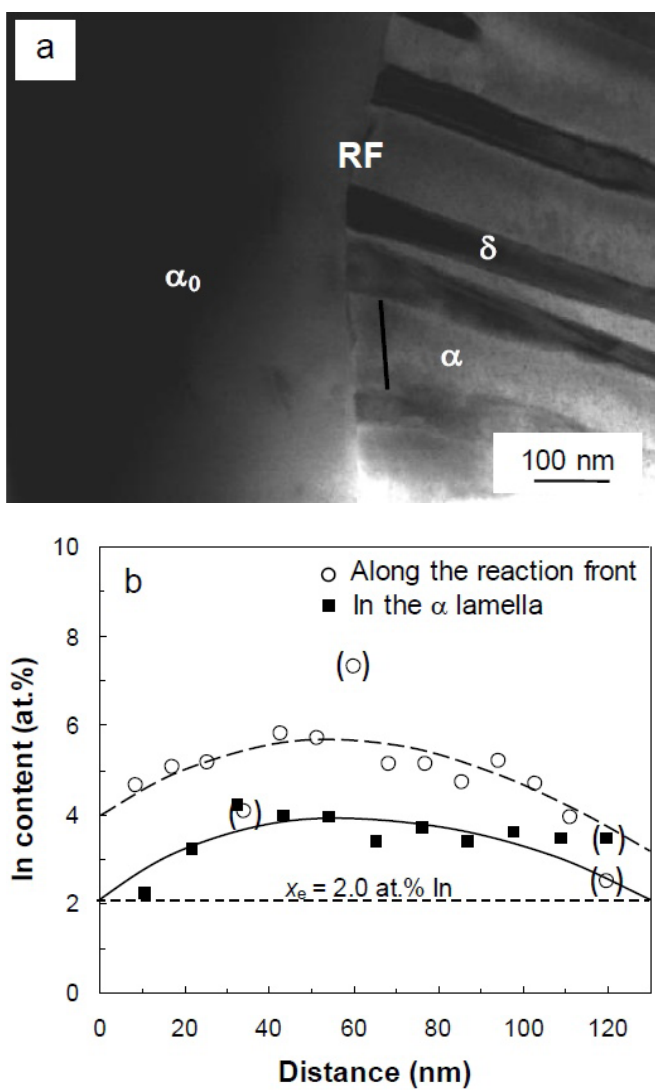

Fig. 10. (a) TEM image of the reaction front of a discontinuous precipitation reaction in $\mathrm{Cu}-7.5 \mathrm{at} . \% \mathrm{In}$ annealed at $603 \mathrm{~K}$ for $48 \mathrm{~h}$. (b) Concentration profiles determined by EDX along the RF and in the In-depleted $\alpha$ lamella. Reprinted with permission from Trans Tech Publications, G.A. Lopez, P. Zieba, W. Sigle, E.J. Mittemeijer: Defect and Diffus. Forum 2005, 237-240, 1230-1233, Fig. 1 [33]

Quit recently Suguihiro et al. [34] examined microstructure evolution in the $\mathrm{Cu}-10$ at.\% Co melt-spun ribbons. The discontinuous reactions were the most favorite mode of phase transformations. The columnar grains resulting from the meltspinning induced the grain boundaries to move with simultaneous formation and growth of the rod-like precipitates. The DP predominated especially at low temperatures, at higher ones the discontinuous coarsening (DC) reaction was also observed. Figure 11 presents the microstructure of discontinuously coarsened product after annealing at $783 \mathrm{~K}$. Even after DC the spacing between two Co-rich rods was extremely small not exceeding
$40 \mathrm{~nm}$. There was also no substantial differences between Co-rich and $\mathrm{Cu}$-rich arrays. Based on the EDX results, it was difficult to judge whether the state of equilibrium after the DC reaction was attained.
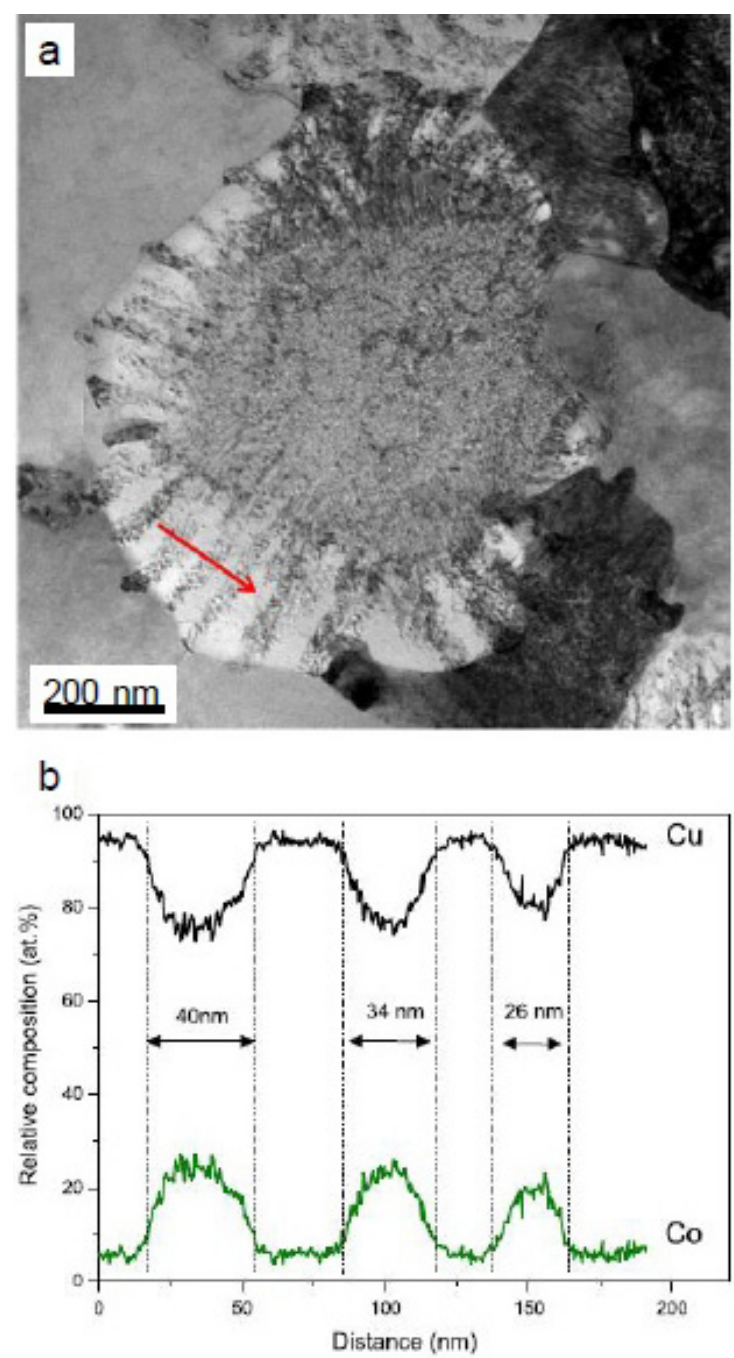

Fig. 11 a) STEM BF image of DC reaction in $\mathrm{Cu}-10$ at.\% Co after 60 min of annealing at $783 \mathrm{~K}$. b) EDX line scan made along line indicated by arrow. Reprinted with permission from Springer, N.M. Suguihiro, Y.T. Xing, D. Haeussler, W. Jaeger, D.J. Smith, E. Baggio-Saitovitch, I.G. Solórzano: J. Mater., Sci. 2014, 49, 6167-6179, Fig. 5 [34]

Rojhirunsakool, Nag and Banerjee [35] examined DP reaction after annealing at $873 \mathrm{~K}$ for $10 \mathrm{~min}$ of Ni-37.5Co-12.5Al at. $\%$. Discontinuous $\gamma+\gamma^{\prime}$ product was completely transformed throughout the grain after $873 \mathrm{~K} / 1 \mathrm{~h}$. On long term annealing $(873 \mathrm{~K} / 256 \mathrm{~h})$, coarser $\gamma+\gamma^{\prime}$ lamellae products of equilibrium concentration replaced the fine discontinuous precipitates. Figure 12 shows an atom probe tomography (APT) reconstruction of volume $60 \times 60 \times 50 \mathrm{~nm}^{3}$ that captured a lamellar structure of alternating $\gamma$ and $\gamma^{\prime}$ phases. Co ions (blue) represent the $\gamma$ phase while $\mathrm{Al}$ ions (red) represent the $\gamma^{\prime}$ phase. Ni ions were omitted for clarification.

Alili et al. [36] measured the solute concentration profiles across the a lamellae in the ternary $\mathrm{Cu}-15 \mathrm{Ni}-8 \mathrm{Sn}(\mathrm{wt} \%)$ alloy (in binary $\mathrm{Cu}-\mathrm{Ni}$ alloy DP does not occur). Figure 13 presents 
a
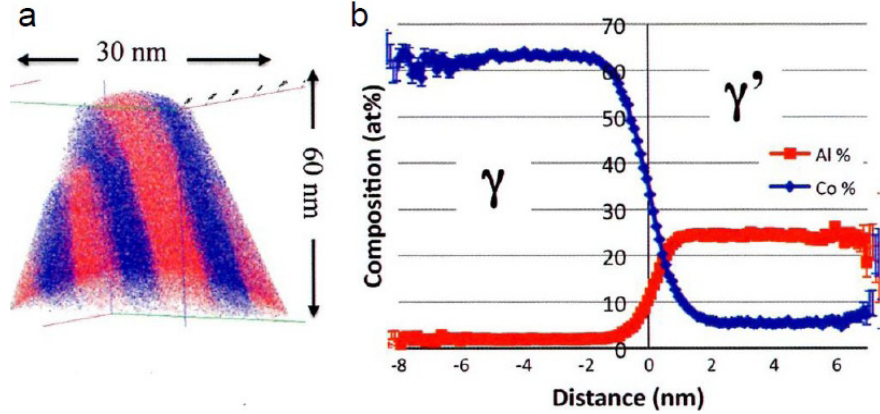

Fig. 12. a) APT reconstruction of DP product in the Ni-37.5Co-12.5Al (at.\%) alloy annealed at $873 \mathrm{~K} / 256 \mathrm{~h}$. Co ions are blue and $\mathrm{Al}$ ions are red. b) Compositional profile across $\gamma / \gamma^{\prime}$ interface of $\mathrm{Al}$ and Co. Reprinted with permission from the Minerals, Metals \& Materials Society, T.P. Rojhirunsakool, S. Nag, R. Banerjee: JOM 2014, 66, 1465-1470, Fig. 4d [35]

the X-ray maps of $\mathrm{Cu}, \mathrm{Ni}, \mathrm{Sn}$ in a duplex lamellar region. The depletion in $\mathrm{Ni}$ and $\mathrm{Sn}$ within the $\alpha$ lamella is clearly visible. This is confirmed by the line scan made across several $(\alpha+\gamma)$ lamellae (where the sharp peaks indicate the $\mathrm{Ni}$, Sn enrichment and $\mathrm{Cu}$ depletion in the $\gamma$ phase. The quantitative EDX performed to estimate the partitioning of the elements in the $\alpha$ lamellae revealed still significant amount of $\mathrm{Ni}$ content approaching 8 wt.\% in average and only $2.1 \mathrm{wt} . \%$ of Sn. On the other hand, the EDX analysis for the $\gamma$ lamellae was performed only in the areas where the $\alpha$ lamellae were removed by selective etching. In such case the results of EDX analysis were not sensitive to the X-ray signal coming from the surrounding $\alpha$ lamellae. The obtained data showed 5 times higher content of $\mathrm{Ni}$ and 15 times higher content of $\mathrm{Sn}$ in comparison to the $\alpha$ lamellae. It means that also third element added to the binary A-B alloy is mostly located in the solute-rich lamellae created due to the DP reaction. However, the formula of the $\gamma$ lamellae is still close to $\left(\mathrm{Cu}_{3} \mathrm{Sn}\right)$, which indicates that some $\mathrm{Cu}$ atoms are replaced by $\mathrm{Ni}$.
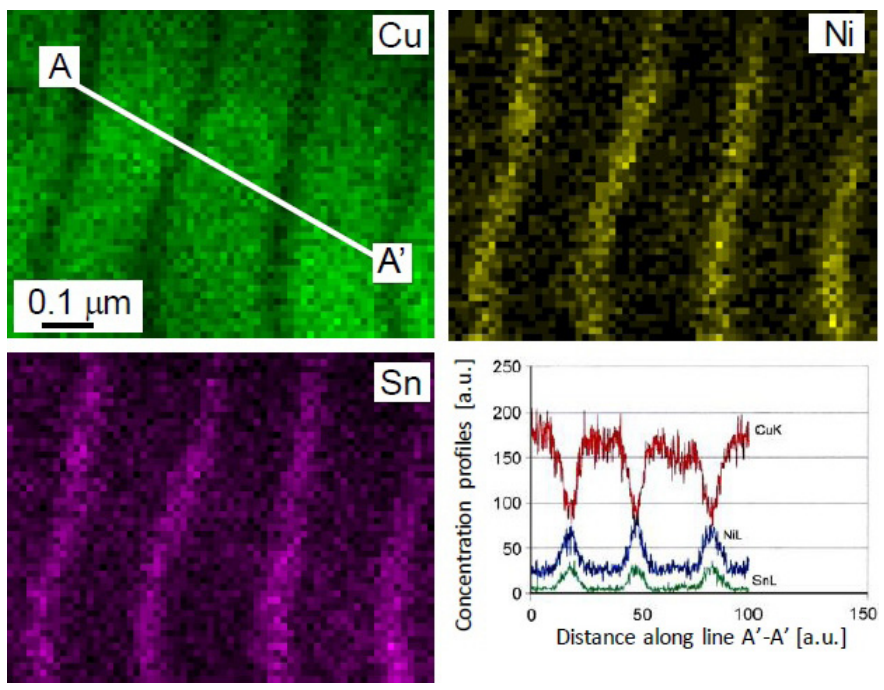

Fig. 13. EDX maps of $\mathrm{Cu}, \mathrm{Ni}$, and $\mathrm{Sn}$ taken from the set of $\alpha$ and $\gamma$ lamellae and EDX line scan made along AA' line. Cu-15Ni-8Sn alloy aged at $775 \mathrm{~K}$ for $1000 \mathrm{~s}$. Reprinted with permission from Elsevier Inc., B. Alili, D. Bradai, P. Zieba: Mater. Charact. 2008, 59, 1526-1530, Fig. 6 and 5 [36]

\section{Relation to GB orientation}

The dependence between misorientation angle and incubation period and cell growth velocity for the DP reaction at [011] symmetric tilt boundaries in $\mathrm{Cu}-0.75 \mathrm{wt} \%$ Be alloy bicrystals was studied by Monzen [37] using TEM technique. Lower-energy boundaries were found to exhibit a longer incubation period and a slower growth rate.

Similar examination was performed by Boonyachut and Laughlin [38] for Cu-3wt.\% Ti alloy using TEM technique and electron back-scatter diffraction (EBSD). The studies showed, as expected, that discontinuous precipitates were not observed on twin boundaries which are example as special ones with low energy. Moreover, the GBs with a special CSL relationship were not covered with discontinuous precipitates. However, discontinuous precipitation did not also occur at all the boundaries considered as random high angle ones. This means that some preferences exist resulting from differences in the grain boundary structure and energy in the specific sites. From this point of view, further studies of the grain boundary plane inclination and other factors such as the orientation between precipitates habit plane and the grain boundaries are necessary.

On the other hand, Wang et al. [39] study of the DP reaction in a Cu-8.6at\% Sn alloy annealed at $573 \mathrm{~K}$ for $1.47 \times 10^{6} \mathrm{~s}$ provided evidences that the new forming phase was not $\varepsilon$ phase but the $\xi$ phase which was stable above $835 \mathrm{~K}$. The EBSD measurements revealed that the orientation of the Sn depleted $\alpha$ phase is often correlated with that of the $\alpha_{o}$ grain from which DP started. Possible orientations of the $\alpha$ phase were determined as supervariants to the adjoining $\alpha_{o}$ grains mediated by the $\xi$ phase.

\section{Role of external stresses and plastic deformation}

The influence of applied stress on the DP reaction in a Cu-2.1wt \% Be alloy aged at $300^{\circ} \mathrm{C}$ was examined by Monzen et al. [40]. A compressive stress accelerated the growth of DP cells, which consisted of lamellae of the new $\gamma$ phase and the solute-depleted $\alpha$ phase, but a tensile stress did not essentially change it. The cell growth rates along the loading direction under the compressive and tensile stress were the same as those along the direction perpendicular to the loading direction under the same stress. Both the compressive and tensile stresses had no influence on the incubation time to initiate DP. However, specific $\gamma$ variants among crystallographically equivalent ones were found to be formed, depending on the sense of the applied stress. This result, together with the dependence of the cell growth rate on the sense of the applied stress, can be well understood through the interaction energy between the external stress and the misfit strains of discontinuous $\gamma$ precipitates.

Monzen [41] examined also the effect of 0.01 and $0.03 \mathrm{wt} \%$ $\mathrm{Mg}$ on the bend formability and strength of a $\mathrm{Cu}-1.8 \mathrm{Be} 0.21 \mathrm{Co}$ $(\mathrm{wt} \%$ ) alloy aged at $593 \mathrm{~K}$ for $1800 \mathrm{~s}$. The addition of $\mathrm{Mg}$ to the $\mathrm{Cu}-\mathrm{Be}-\mathrm{Co}$ alloy enhanced the bend formability and strength of 
the alloy. The enhancement of strength is caused by the increase in volume fraction of $\gamma_{1}^{\prime}$ precipitates in the $\mathrm{Cu}$ matrix. In bending of the alloys with and without 0.01 and $0.03 \mathrm{wt} \% \mathrm{Mg}$, a number of micro necks first appeared along GBs, and part of them grew, resulting in surface wrinkles, which finally led to surface cracking. The cracking was initiated from voids formed by destruction of bar-like $\gamma$ precipitates in DP cells and propagated along GBs. The addition of $\mathrm{Mg}$ decreased the width of DP cells, resulting in better bend formability. This was due to smaller stress concentration because less inhomogeneous deformation developed in the cells and, as a result, destruction of the $\gamma$ precipitates in cells occurred less easily as the cell width decreased.

An extensive research of third elements addition on the microstructure and mechanical properties of $\mathrm{Cu}$-Ti alloys after prior cold working was performed by Markandeya et al. [42-44]. They examined influence of $\mathrm{Cd}, \mathrm{Cr}$, and $\mathrm{Zr}$ with the conclusion that maximum strength is mainly attributed to fine scale precipitation of metastable and coherent $\beta^{\prime}-\mathrm{Cu}_{4}$ Ti phase. On overageing at 723 or $773 \mathrm{~K}$, the alloy showed a decrease in hardness as a result of formation of equilibrium precipitate $\beta-\mathrm{Cu}_{3} \mathrm{Ti}$ due to continuous precipitation within the matrix and DP reaction at the GBs. Also, the morphology of the DP reaction changed to a globular form on high deformation.

Other research by Monzen et al. [45] focused on the influence of applied stress on DP was performed for a $\mathrm{Cu}-5 \mathrm{wt} \% \mathrm{Ag}$ alloy aged at $573 \mathrm{~K}$. A tensile stress enhanced the growth of DP cells in both the loading direction (LD) and transverse direction (TD), but the cell growth rate in the TD, $v_{C T}$, was faster than that in the $\mathrm{LD}, v_{C L}$. A compressive stress suppressed the cell growth in the TD, but did not significantly influence it in the LD. The tensile or compressive stress tended to produce discontinuous silver precipitates elongated in $\mathrm{a}<110>{ }_{\alpha}$ direction of the copper matrix in a DP cell, nearly perpendicular to or parallel to the LD. This result, along with the dependence of the cell growth rate on the sense of the applied stress, can be understood again through the interaction energy between the external stress and the misfit strains of silver precipitates. An analysis of lengthchange measurement results has enabled estimation of the ratio of the growth rate of silver precipitates in the TD, $v_{P T}$, to that in the $\mathrm{LD}, \mathrm{v}_{\mathrm{PL}}$, under tension or compression. The obtained ratios were in good agreement with the values of $v_{P T} / v_{P L}$, experimentally determined, indicating that the anisotropy of the cell growth rate is determined by the growth behavior of silver precipitates.

$\mathrm{Ng}$ et al. [46] investigated the DP reaction in a supersaturated Al-14.6at.\% Zn alloy in relation to different forms of deformation structures. The intense surface scribing, followed by short-term ageing at $338 \mathrm{~K}$, resulted in a recrystallized duplex structure with nanoscale equiaxed beta- $\mathrm{Zn}$ particles and alpha-Al grains. Moderate surface grinding increased the transformation kinetics of DP on the alloy surface by an order of magnitude compared to that of the undeformed counterpart. Such behaviour was attributed to intragranular nucleation and growth of DP colonies associated plausibly with dislocation cell wall structures induced by the surface strain. On the other hand, bulk deformation by means of cold-rolling (13-66\% reduction) and in situ stress-ageing (similar to $1 \%$ strain) both suppressed the development of DP in the alloy. The deformation heterogeneities such as deformation bands and, maybe, dislocation cell wall structures, acted as preferred nucleation sites for discontinuous products or as potential barriers.

\section{The effect of third element}

The influence of $\mathrm{Zr}$ and $\mathrm{P}$ additions on the microstructure and tensile ductility at room temperature of a $\mathrm{Cu}-4.2 \mathrm{Ni}-1.0 \mathrm{Si}$ (wt\%) forged alloy was investigated by Tanaka et. al. [47]. The DP reaction and age hardening due to appearance of $\mathrm{Ni}_{2} \mathrm{Si}$ in the alloy was delayed by $\mathrm{Zr}$ and $\mathrm{P}$ additions.

Other study by Semboshi et al. [48] reported the effects of boron doping on the microstructural evolution, mechanical and electrical properties of age-hardenable $\mathrm{Cu}-4$ at.\% Ti alloys. The discontinuous precipitates composed of the stable $\beta-\mathrm{Cu}_{4} \mathrm{Ti}$ and solid-solution lamellae are then formed and grown at the GBs. However, the volume fraction of the discontinuous precipitates was lower in the $\mathrm{Cu}-4 \mathrm{Ti}-0.03 \mathrm{~B}$ alloy than in the $\mathrm{Cu}-4 \mathrm{Ti}$ alloy, particularly after over-ageing for 72-120 h. The suppression of the formation of discontinuous precipitates resulted in the improvement of the hardness and tensile strength. It should be noted that minor $\mathrm{B}$ doping of $\mathrm{Cu}$-Ti alloys also effectively enhanced tendency to fracture, which should be attributed to segregation of $B$ at the GBs.

The influence of several elements on the behaviour of DP reaction in Ni-Cr system was investigated by Ueta, Hida and Kajihara [49, 50]. They used $\mathrm{Ni38Cr}$ as the reference alloy, then added $0.9 \mathrm{Fe}, 3.2 \mathrm{~W}, 1.7 \mathrm{Mo}, 1.0 \mathrm{Co}, 1.2 \mathrm{Cu}, 0.89 \mathrm{~V}$ (wt.\%) and annealed at temperatures of $873-1023 \mathrm{~K}$ for various time up to $2300 \mathrm{~h}$. The cell growth was retarded by $\mathrm{W}$ and Mo but not by $\mathrm{Fe}$. The retardation was more remarkable for Mo than for W. On the other hand, the cell growth was slightly accelerated by $\mathrm{Cu}$ but not by $\mathrm{Co}$ and $\mathrm{V}$. The use of Aaronson-Liu diffusion model shown that the boundary diffusion of $\mathrm{Cr}$ along the moving cell boundary was decelerated by $\mathrm{W}$ and Mo but slightly accelerated by $\mathrm{Fe}$. Other alloying elements $(\mathrm{Cu}, \mathrm{V}, \mathrm{Co})$ shown scarcely effect on the boundary diffusion.

The systematic studies of third element influence on growth rate and $\mathrm{GB}$ diffusivity in $\mathrm{Cu}-4.35$ at.\% alloy was performed by Gatsenko et al. [51]. The growth rate of DP colonies determined at $873 \mathrm{~K}$ was higher for 0.5 at. $\% \mathrm{Ni}$ and 0.5 at.\% In additions but lower in the case of $0.4 \mathrm{Ga}, 0.5 \mathrm{Mn}, 0.5 \mathrm{Co}, 0.6 \mathrm{Cr}, 0.5 \mathrm{Fe}, 0.3 \mathrm{Sn}$ and $0.3 \mathrm{Zr}$. The same tendency was exhibited by the GB diffusivity. Based on these results, Lyashenko et al. [52] determined the enthalpy of the GB segregation taking into account both the calculation of the chemical enthalpy of mixing of components and enthalpy of elastic interaction depending on the different size of atoms. It was found that $\mathrm{Ni}$ addition enhanced the growth rate of DP in $\mathrm{Cu}-4.35 \mathrm{at} \% \mathrm{Ti}$ alloy whereas $\mathrm{Co}$ addition reduced this rate. Such behavior was attributed to large differences in the enthalpies of mixing in the bulk of grains. 


\section{Examples of DP reaction in other alloys}

\subsection{Copper-titanium alloys}

An excellent review of the phase transformations occurring in $\mathrm{Cu}-\mathrm{Ti}$ alloys was presented by Soffa and Laughlin [53]. One should note, that the research in $\mathrm{Cu}$-Ti system became popular with the goal to develop high strength ternary alloys in order to substitute toxic and expensive $\mathrm{Cu}-\mathrm{Be}$ alloys. In $\mathrm{Cu}-\mathrm{Ti}$ alloys, the DP reaction is observed after over ageing and is associated with the emergence of a coarse lamellar microstructure which nucleates at the grain boundaries of the parent matrix phase and the growth of these cells consumes the metastable, finescale coherent/semicoherent phase mixtures leading to a rapid degradation of mechanical properties. The activation energy for the DP growth is less than half that for bulk diffusion indicating interfacial/boundary diffusion control.

Other systematic approach to the DP reaction in the $\mathrm{Cu}-\mathrm{Ti}$ system was presented by Gatsenko et al. [54]. They investigated cellular precipitation in $820-970 \mathrm{~K}$ temperature range for $\mathrm{Cu}$ with 3.68, 4.46, 4.98 and 5.69 at. \% Ti alloys. Kinetic and thermodynamic cellular precipitation parameters were determined by a quantitative metallography and X-ray diffraction. The determined growth rate, the thickness of $\alpha$ lamella, average solute concentration in the $\alpha$ lamella enabled calculation of the GB diffusion coefficient of Ti and activation energies. Moreover, the values of Gibbs energy changes accompanied the DP reaction were estimated together with segregation factor. It was found that segregation factor increases at whole range ageing temperatures for $\mathrm{Cu}$ with 4.46, 4.98 and 5.69 at.\% Ti alloys but for $\mathrm{Cu}$ with 3.68 at. \% Ti alloy such tendency was not obvious.

\subsection{Discontinuous precipitation in superalloys}

In the Ni-based superalloys DP reaction leads to the formation and growth of brittle and harmful topologically closed packed (TCP) phases. In the two components' $\gamma / \gamma^{\prime}$ microstructure of nickel-base superalloys, the DP is driven by the supersaturation of the $\gamma$ matrix with refractory elements and can be described by the following equation:

$$
\left(\gamma_{\text {matrix }}+\gamma_{\text {precipitates }}^{\prime}\right) \rightarrow\left(\gamma_{\text {matrix }}^{\prime}+\gamma_{\text {precipitates }}\right)+\mathrm{TCP}
$$

where $\gamma_{\text {matrix }}$ is in supersaturated state. The substantial difference compared to the binary system is that supersaturated $\gamma$ matrix changes into $\gamma$ precipitates, whereas the former $\gamma^{\prime}$ precipitates become the new matrix after the discontinuous transformation. Such situation does not occur in the DP in binary system, where the matrix system remains the same.

Figure 14 presents coarse and TCP-containing microstructure of the DP at the GB and the original fine $\gamma / \gamma^{\prime}$ structure in the surrounding area. The TCP phase appears in a rather globular or elongated morphology $[55,56]$. Much more detailed insight into morphology of TCP phase was obtained using 3-D tomography (Fig. 15). At the beginning of the DP reaction, an increased number of TCP nuclei form at the original GB. Only a few of these nuclei grow with the progressing DP front with a tilt angle of 20 to $30 \mathrm{deg}$ to the reaction front normal. Resulting TCP microstructure appears as branching columns, but not as perfect lamellae. The EPMA analysis in the enlarged TCP-containing section showed that TCP phase is enriched with Re, W, Mo, and $\mathrm{Cr}$, whereas $\mathrm{Al}$ and Ta are hardly soluble within this phase. Moreover, in front of the DP reaction depletion of Re and $\mathrm{W}$ as well as an enrichment of $\mathrm{Co}$ and $\mathrm{Cr}$ occurred.

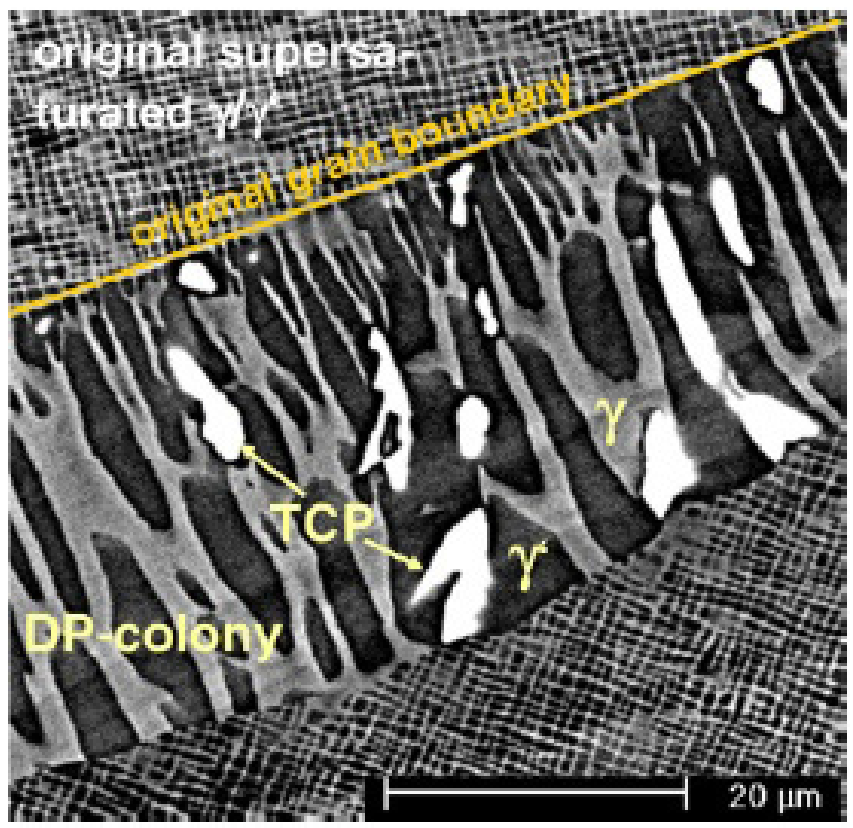

Fig. 14. SEM image of the developed TCP phases in Astral-20 alloy aged $1000 \mathrm{~h}$ at $1323 \mathrm{~K}$. Reprinted with permission from Elsevier Inc., A. Heckl, S. Cenanovic, S. Neumeier, M. Goken, R.F. Singer: Acta Mater. 2011, 59, 6563-6573, Fig. 1b [55]

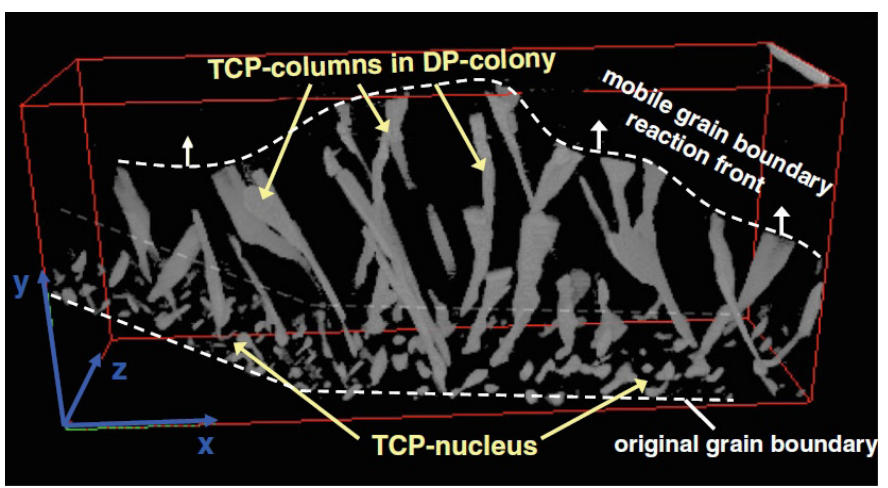

Fig. 15 . The DP colony in the Astra1-20 alloy aged $1000 \mathrm{~h}$ at $1223 \mathrm{~K}$. The reconstructed volume equals $95 \times 26 \times 32 \mathrm{~mm}^{2}$. Reprinted with permission from Springer International Publishing AG, A. Heckl, S. Cenanovic, M. Goken, R.F. Singer: Metall. Mater. Trans. A 2012, 43, 10-19, Fig. 3 [56]

Another possibility for DP can be observed but in strictly limited region beneath an aluminized or Pt-aluminized surface coating. In this case the reaction can be written as: $\gamma+\mathrm{Al} \rightarrow$ $\gamma^{\prime}+$ TCP and the DP zone is also referred to as the secondary reaction zone (SRZ). 
Liu et al. [57] observed for the first time the DP reaction in the Ni-18 at.\% Ru alloy. These alloys are excellent candidates for electrical contact applications due to combination of a low-resistivity selfhealing native oxide scale and good wear properties. It was shown that the $\beta$ phase formed by the discontinuous lamellar decomposition from nucleation sites on $\alpha$ grain boundaries.

\subsection{Discontinuous precipitation and discontinuous coarsening in nitrided Fe based alloys}

Nitriding is a thermochemical surface engineering treatment of the alloys during which, the surface of the specimen achieves equilibrium with the nitriding atmosphere and nitrogen dissolution in the ferrite $(\alpha-\mathrm{Fe})$ occurs. Dissolved nitrogen starts diffusing in the ferrite. Interaction of nitride forming alloying element with diffusing nitrogen leads to the formation of nitride precipitate. Quite recently, Hosmani [58] summarised the research performed for the $\mathrm{Fe}-\mathrm{V}$ and $\mathrm{Fe}-\mathrm{Cr}$ alloys containing high concentration of alloying elements. In these alloys nitriding resulted in the "discontinuous coarsening" of the former continuous precipitates. This discontinuous coarsening involves the growth of $\alpha-\mathrm{Fe}$ and $\mathrm{VN}$ or $\mathrm{CrN}$ lamellae from nucleation sites like surfaces and GBs. The following reaction possibly operates during DC of nitride precipitates: $\alpha^{\prime}+\beta^{\prime} \rightarrow \alpha+\beta$, where $\beta^{\prime}$ denotes coherent nitride precipitates in a supersaturated (with nitrogen) ferrite matrix $\left(\alpha^{\prime}\right)$.

The reaction consists in replacing the submicroscopical and coherent/semi-coherent nitride precipitates by nitride lamellae $\left(\beta^{\prime} \rightarrow \beta\right)$ with simultaneous elimination of the nitrogen supersaturation of the ferrite matrix $\left(\alpha^{\prime} \rightarrow \alpha\right)$. Therefore, on nitriding of $\mathrm{Fe}-\mathrm{V}$ and $\mathrm{Fe}-\mathrm{Cr}$ alloys that contain high concentrations of alloying elements, the following two reaction fronts can be expected: (i) initially, inward diffusion of nitrogen and the reaction of alloying element with $\mathrm{N}$ to form finely dispersed coherent/ semi-coherent nitride precipitates and then (ii) subsequent DC of the former continuous precipitates.

The DC depends on the concentration of alloying elements. This precipitation morphology is observed for nitrided alloys containing high concentration of alloying elements (more than about $2 \mathrm{wt} \%$ of alloying elements). However, these precipitation morphologies are not reported in the literature for nitrided $\mathrm{Fe}-\mathrm{Ti}$ and Fe-Al alloys [58].

Other behaviour was observed by Selg et al. [59] in the recrystallized and cold rolled Fe-1at.\% Mo-alloy at $853 \mathrm{~K}$ in a $\mathrm{NH}_{3} / \mathrm{H}_{2}$ gas mixture. The nitride precipitation starts with the formation of submicroscopical $\mathrm{Mo}_{2} \mathrm{~N}$-type precipitates (no indication of $\alpha^{\prime \prime}$-(Fe, Mo) ${ }_{16} \mathrm{~N}_{2}$-type precursors was obtained) followed by a discontinuous transformation of the type:

$$
\alpha^{\prime}+\gamma \rightarrow \alpha+\delta^{\prime}
$$

where $\alpha^{\prime}$ denotes the supersaturated, distorted ferrite-matrix, $\gamma$ represents the submicroscopical likely largely coherent $\mathrm{Mo}_{2} \mathrm{~N}$ type precipitates and $\alpha$ and $\delta$ represent the ferrite and MoN-

type lamellae in the colonies produced by the discontinuous transformation starting from mobile GBs in the ferrite matrix. Because the crystal structures of $\gamma$ and $\delta$ are not identical, the discontinuous transformation in this case is a pure discontinuous precipitation reaction and cannot be considered as a discontinuous coarsening reaction discussed previously.

The occurrence of DP reaction in multicomponent $\mathrm{Fe}-\mathrm{Cr}-$ Mn-N system was reviewed by Srinivas [60]. This system is ideal for the study of discontinuous precipitation in multi-component systems because: (i) the steels investigated contain the substitutional solutes $\mathrm{Cr}$ and $\mathrm{Mn}$ as well as the interstitial solute nitrogen and (ii) a single precipitate namely, $\mathrm{Cr}_{2} \mathrm{~N}$, is predominantly observed which simplifies the study of its growth behaviour.

Figure 16 shows schematically the development of DP with corresponding changes of nitrogen concentration. In the solution treated sample, the concentration of nitrogen is uniform everywhere and is represented by $N_{s}$ in Fig. 16a. During ageing, $\mathrm{Cr}_{2} \mathrm{~N}$ lamellae form by absorption of nitrogen from the immediate surrounding matrix, which then becomes highly depleted in nitrogen. The concentration of nitrogen in the cell matrix $\left(N_{c m}\right)$ decreases with the formation of lamellae while the concentration of nitrogen in the untransformed matrix $N_{u m}$ remains the same as $N_{s}$ as given in Fig. 16b. This sets up a large concentration gradient between the untransformed matrix and the cell matrix resulting in the flow of nitrogen from the former to the latter. Thus, long-range diffusion of nitrogen from untransformed matrix is necessary for the growth of $\mathrm{Cr}_{2} \mathrm{~N}$ lamellae (Fig. 16c). With the progress of ageing, the nitrogen concentration in the untransformed matrix $\left(N_{u m}\right)$ decreases and nitrogen concentration in the cell $\left(N_{c}\right)$ increases as more and more nitrogen diffuses to accomplish growth. As a result of the continuous reduction in the nitrogen concentration gradient between the untransformed matrix and the cell matrix, diffusion rate of nitrogen and hence the migration rate of cell boundary decreases with reaction time.

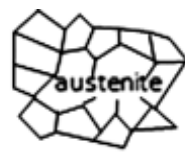

(a)
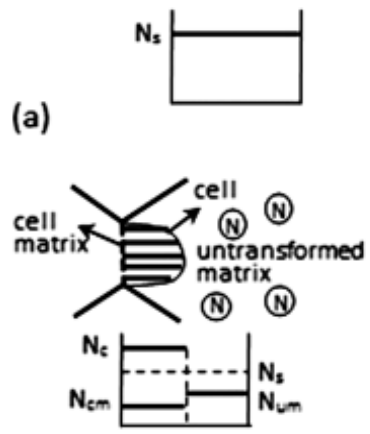

(c)

(d)

(b)

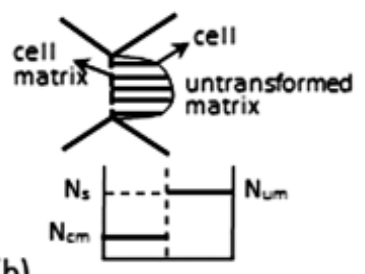

Fig. 16. Growth mechanism for discontinuous precipitation in $\mathrm{Fe}-\mathrm{Cr}-$ Mn-N system: (a) nitrogen concentration in solution treated samples, (b) formation of cells after ageing at $t=t_{1}$, (c) nitrogen diffusion at $t=t_{2}$, (d) termination of cell growth at $t=t_{3}$. Redrawn with permission from Elsevier Inc., N.C.S. Srinivas, V.V. Kutumbarao: Scripta Mater. 2004, 51, 1105-1109, based on Fig. 1 [60] 
As ageing progresses, $N_{u m}$ decreases further. Eventually, when chemical equilibrium is attained i.e. when $N_{u m}$ equals $N_{c m}$ as shown in Fig. 16d, the cell growth stops leading to incomplete cellular reaction.

Wang et al. [61] focused on detailed research of stainless steels, as only limited studies of DP reactions have been performed, so far in those alloys. They observed the DP of $\mathrm{Cr}_{2} \mathrm{~N}$ nitride lamellae in high-nitrogen $\mathrm{Cr}-\mathrm{Mn}$ austenitic stainless steel after ageing and lamellar $\mathrm{M}_{23} \mathrm{C}_{6}$ carbide in $\mathrm{Cr}-\mathrm{Ni}$ austenitic stainless steel. Moreover, studies of Peng et al. [62] reported for the AISI 304 austenitic stainless steel after nitriding at high temperature $(>1073 \mathrm{~K})$ a coarse lamellar structure of austenite and $\mathrm{Cr}_{2} \mathrm{~N}$ which was developed in the front of fine lamellae composed of austenite and $\mathrm{CrN}$.

Atom-probe tomography was used by Wang et al. [61] to fully characterize the cellular precipitation zone. Figure $17 \mathrm{a}$ shows a rectangular region of interest containing the lamellar nitride layer parallel to the original austenite-ferrite interface. The lamellar spacing was ca $10 \mathrm{~nm}$ in each elemental column. The $\mathrm{Cr}, \mathrm{Al}$ and $\mathrm{N}$ distributions strongly overlapped, suggesting nitride formation. On the other hand, $\mathrm{Fe}$ - and Ni-enriched lamellae intertwine with $\mathrm{Cr}$-Al nitrides in the reconstructions are shown in Figure 17b. In order to identify the composition of the lamellar nitride formed at the austenite-ferrite interface, a proxigram from a randomly chosen nitride within the lamellar structure is shown in Fig. 17b. Besides the enrichment of $\mathrm{Cr}$, $\mathrm{Al}$, and nitrogen in the nitride, $\mathrm{Fe}$ and $\mathrm{Ni}$ were rejected into the neighbouring region. Major elements in the nitride (between 0 - and 1-nm markers) are $\mathrm{Fe}, \mathrm{Cr}$, and nitrogen, concentrations of which are about 23, 36, and 23 at.\%, respectively. Wang et al. [62] concluded based on electron diffraction data that the nitride phase at the interface is face-centered cubic $(f c c)$, most likely rocksalt-structured $(\mathrm{Cr}, \mathrm{Al}, \mathrm{Fe}) \mathrm{N}_{1-\mathrm{X}}$. Therefore, the cellular precipitation reaction can be written as $\gamma_{N} \rightarrow \beta+\alpha$ where $\gamma_{N}$ is the nitrogen-supersaturated austenite, $\beta$ is $\mathrm{MN}_{1-\mathrm{X}}$, and $\alpha$ is the ferrite with $\alpha$ minimum nitrogen concentration.

Recent studies on ternary Fe-Cr-Al [63] and Fe-Cr-Ti [64] alloys showed that in the ternary alloys also cubic NaCl-type, "mixed" ternary $\mathrm{CrxAl}_{1-\mathrm{X}} \mathrm{N}$, and $\mathrm{Cr}_{\mathrm{x}} \mathrm{Ti}_{1-\mathrm{X}} \mathrm{N}$ nitride platelets develop along $\{100\}$ lattice planes of the ferrite matrix and in accordance with a Baker-Nutting orientation relationship. Similar research performed by Kang et al. [65] in quaternary Fe-based alloys also allowed to identify "mixed" nature of a quaternary $\left(\mathrm{Cr}_{\mathrm{X}}, \mathrm{V}_{\mathrm{Y}}, \mathrm{Mo}_{1-\mathrm{X}-\mathrm{Y}}\right) \mathrm{N}$ nitride

\section{Concluding remarks}

First of all it should be noted that discontinuous reactions are relevant examples of nano-phase transformations in relation to changes of solute content and distance of diffusion processes. The understanding the mechanism and kinetics of these reactions requires the use of very sophisticated analytical tools. Unfortunately, in spite of the huge progress in the instrumentation there are still some challenges like details of solute redistribution
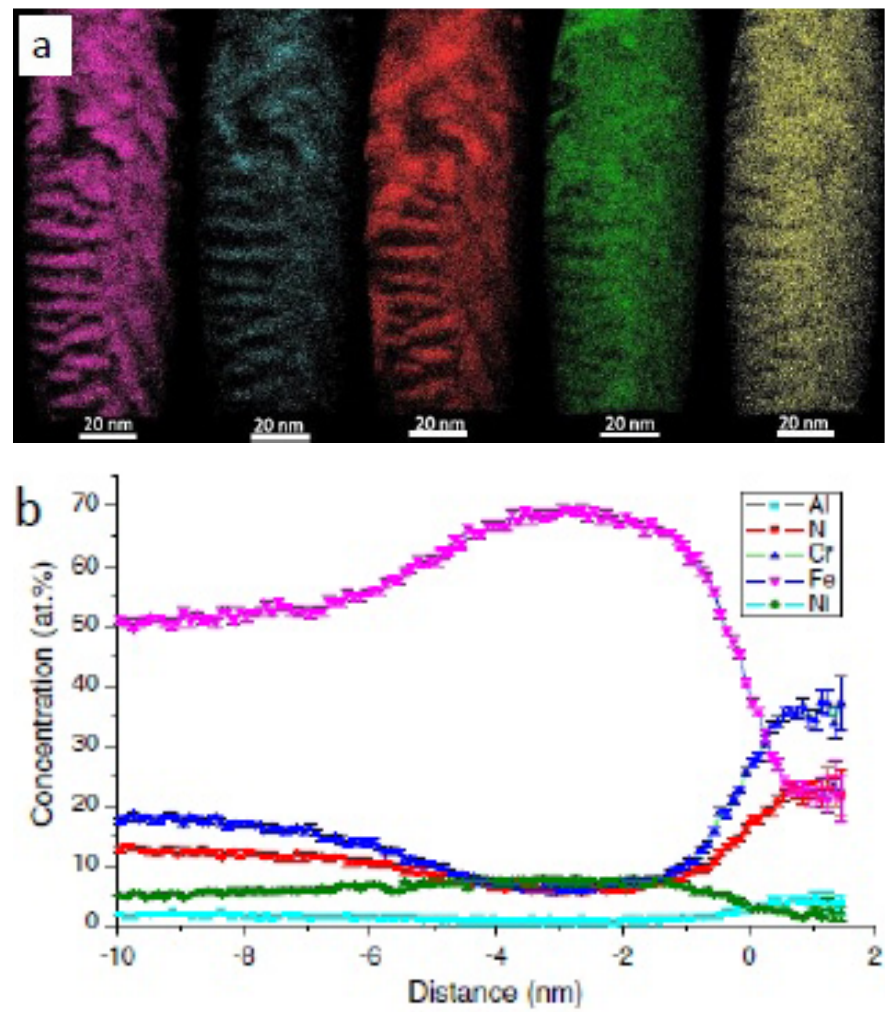

Fig. 17. a) Lamellar nitride region: (a) through (e) are Cr-, Al-, N-, $\mathrm{Ni}-$, and Fe-reconstructions, respectively. b) Proxigram from a random nitride lamella. Fe17Cr7Ni1 Al (wt\%) alloy nitrided 713K/ $20 \mathrm{~h}$. With permission from Springer International Publishing AG, D. Wang, F. Ernst, H. Kahn, A.H. Heuer: Metall. Mater. Trans. A 2014, 45, 35783585 , Fig. 4 and 5 [61]

across the reaction front and within solute depleted lamella, especially for new types of discontinuous reactions. During last decade only a little attention was paid at in-situ studies to predict the RF shape and solute concentration profile. In this context modelling is a promising tool but further studies are necessary in order to be closer to reality. Another important direction is related to determination of rate controlling factor (GB diffusivity). Most of the research simply ignores this problem which makes the research report rather incomplete. Therefore, more effort should be concentrated on the discontinuous reactions itself but not on the "side effect" accompanying other phenomena.

\section{REFERENCES}

[1] D.B. Williams, E.P. Butler, Grain boundary discontinuous precipitation reactions, Int. Met. Rev. 26, 153-183 (1981).

[2] W. Gust, Discontinuous precipitation in binary metallic systems, in Phase Transformations, Vol. 1, II-27-II-68, Institution of Metallurgists, London 1979.

[3] P. Zieba, W. Gust, Analytical electron microscopy of discontinuous solid state reactions, Int. Mater. Rev. 43, 70-97 (1998).

[4] I. Manna, S.K. Pabi, W. Gust, Discontinuous reactions in solids, Int. Mater. Rev. 46, 53-91 (2001). 
[5] P. Zieba, Local characterization of the chemistry and kinetics in discontinuous solid state reactions, 2001 Institute of Metallurgy and Materials Science PAS, Cracow.

[6] L.M. Klinger, Y.J.M. Brechet, G.R. Purdy, On velocity and spacing selection in discontinuous precipitation-I. Simplified analytical approach, Acta Mater. 45, 5005-5013, (1997).

[7] I.G. Solorzano, G.R. Purdy, Interlamellar spacing in discontinuous precipitation, Metall. Trans. A 15, 1055-1063 (1984)

[8] I.G. Solorzano, G.R. Purdy, G.C. Weatherly, Studies of the initiation, growth and dissolution of the discontinuous precipitation product in aluminum-zinc alloys, Acta Metall. 1984, 32, 17091717.

[9] L. Klinger, Y. Brechet, D. Duly, On the influence of non-steady state velocity on interlamellae concentration profile in discontinuous precipitation, Scripta Mater. 37, 1237-1242 (1997).

[10] E. Rabkin, W. Gust, Y. Estrin, On dynamic segregation in the discontinuous precipitation reaction, Scripta Mater. 37, 119-124 (1997).

[11] P. Zieba, Some remarks on the magnitude of the chemical diffusivities at moving grain boundaries, Defect Diffus. Forum 249, 173-182 (2006).

[12] L.M. Klinger, Y.J.M. Brechet, G.R. Purdy, Kinetics of multilayer homogenization via coupled grain boundary diffusion and migration: discontinuous homogenization, Acta Mater. 45, 4667-4674 (1997).

[13] Y. Brechet, Ch. Hutchinson, Defect-induced dynamic pattern formation in metals and alloys, in: H. Ehrenreich and F. Spaepen (Eds.), Solid State Physics 2006, 60, 181-286, Elsevier Inc. (USA) 2006.

[14] H.I. Aaronson, M. Enomoto, J. K. Lee, Cellular reactions, in: Mechanisms of diffusional phase transformations in metals and alloys, CRC Press, Boca Raton, London-New York, Taylor \& Francis Group 2020, 543-574.

[15] Y.A. Lyashenko, Choice of optimal regime in cellular decomposition, diffusion-induced grain boundary migration, and the inverse diffusion problem, in: A.M. Gusak (Ed.), Diffusion-controlled solid state reactions in alloys, Thin-Films, and Nanosystems, Willey-VCh 2010, 381-424.

[16] A. Bögel, W. Gust, A stanadardized model and a reaction principle for discontinuous precipitation, Z Metallkd. 79, 296-306 (1988).

[17] K.B. Alexander, The growth kinetics of cellular precipitation, $\mathrm{PhD}$ thesis, Carnegie-Mellon University, Pittsburgh, PA, 1985.

[18] Y.O. Lyashenko, L.I. Gladka, I.O. Shmatko, O.A. Shmatko, Modelling of segregation impact on grain-boundary motion by the example of cellular decomposition of solid solution, Metallofiz. Nov. Tekh. 34, 1693-1713 (2012).

[19] J.D. Robson, Modeling competitive continuous and discontinuous precipitation, Acta Mater. 61, 7781-7790 (2013).

[20] L. Amirouche, M. Plapp, Phase-field modeling of the discontinuous precipitation reaction, Acta Mater. 57, 237-247 (2009).

[21] L. Amirouche and M. Plapp, On the effect of bulk diffusion on the initiation of the discontinuous precipitation reaction: phase-field simulations, Solid State Phenom. 172-174, 549-554 (2011).

[22] T. Duong, R. Arroyave, Multiscale modeling of discontinuous precipitation in U-Nb, in: I. Karaman, R. Arroyave and E. Masad
(Eds.), The TMS Middle East-Mediterranean Materials Congress on Energy and Infrastructure Systems (MEMA 2015), The Minerals, Metals \& Materials Society (TMS), Doha, Qatar, January 2015, pp. 481-490.

[23] R.E. Hackenberg, H.M. Volz, P.A. Papin, A.M. Kelly, R.T. Forsyth, T.J. Tucker, K.D. Clarke, Kinetics of lamellar decomposition reactions in U-Nb alloys, Solid State Phenom. 172-174, 555-560 (2011).

[24] Y.S. Kucharenko, Discontinuous decomposition with precipitation of a liquid phase, Phys. Metal. Metalography 39, 825-820 (1975).

[25] S.P. Gupta, S.K. Goutam, R.S. Babu, Discontinuous precipitation of a liquid in Cu-base alloys - nucleation and growth mechanisms, Z Metallkd. 94, 442-448 (2003).

[26] R.S. Babu, S.P. Gupta, Kinetics of discontinuous precipitation of liquid phase in a Cu-7.4 at.pct. Sn alloy, Can. Metall. Quart. 42, 471-481 (2003).

[27] H. Ramanarayan, T.A. Abinandanan, Phase field study of grain boundary effects on spinodal decomposition, Acta Mater. 51, 4761-4772 (2003).

[28] H. Ramanarayan, T.A. Abinandanan, Grain boundary effects on spinodal decomposition. II. Discontinuous microstructures, Acta Mater. 52, 921-930 (2004).

[29] R. Gronsky, G. Thomas, Discontinuous coarsening of spinodally decomposed Cu- Ni-Fe alloys, Acta Metall. 23, 1163-1171 (1975).

[30] C. Zhao and M.R. Notis, Ordering transformation and spinodal decomposition in Au-Ni alloys, Metall. Mater. Trans. A 30, 7077167 (1999).

[31] S. Gorsse, P. Bellanger, Y. Brechet, E. Sellier, A. Umarji, U. Ail, R. Decourt, Nanostructuration via solid state transformation as a strategy for improving the thermoelectric efficiency of $\mathrm{PbTe}$ alloys, Acta Mater. 59, 7425-7437 (2011).

[32] J. He, S.N. Girard, M.G. Kanatzidis and V.P. Dravid, Microstructure-lattice thermal conductivity correlation in nanostructured PbTe0.7S0.3 thermoelectric materials, Adv. Funct. Mater. 20, 764-772 (2010).

[33] G.A. Lopez, P. Zieba, W. Sigle, E.J. Mittemeijer, Analysis of the diffusion profile along migrating grain boundaries, Defect and Diffus. Forum 237-240, 1230-1233 (2005).

[34] N.M. Suguihiro, Y. T. Xing, D. Haeussler, W. Jaeger, D. J. Smith, E. Baggio-Saitovitch, I. G. Solórzano, Discontinuous reactions in melt-spun $\mathrm{Cu}-10$ at. \%Co alloys and their effect on magnetic anisotropy, J. Mater., Sci. 49, 6167-6179 (2014).

[35] T.P. Rojhirunsakool, S. Nag and R. Banerjee, Discontinuous precipitation of $\gamma^{\prime}$ phase in Ni-Co-Al Alloys, J. Metals 66, 1465-1470 (2014).

[36] B. Alili, D. Bradai, P. Zieba, On the discontinuous precipitation reaction and solute redistribution in a $\mathrm{Cu}-15 \% \mathrm{Ni}-8 \% \mathrm{Sn}$ alloy, Mater. Charact. 59, 1526-1530 (2008).

[37] R. Monzen, C. Watanabe, D. Mino, S. Saida, Initiation and growth of the discontinuous precipitation reaction at [011] symmetric tilt boundaries in $\mathrm{Cu}-\mathrm{Be}$ alloy bicrystals, Acta Mater. 53, 1253-1261 (2005).

[38] N. Boonyachut, D. E. Laughlin, Influence of boundary structure on cellular nucleation in $\mathrm{Cu}-3 \mathrm{w} / \mathrm{oTi}$ age-hardening alloys, J. Mater. Sci. 44, 449-456 (2009). 
[39] Z.-J. Wang, T.J. Konno, Discontinuous precipitation with metastable x phase in a Cu-8.6\% Sn alloy, Philos. Mag. 93, 949-974 (2013).

[40] R. Monzen, T. Hasegawa, C. Watanabe, Effect of external stress on discontinuous precipitation in a $\mathrm{Cu}-2.1 \mathrm{wt} \% \mathrm{Be}$ alloy, Philos. Mag. 90, 1347-1358 (2010).

[41] R. Monzen, T. Hododa, Y. Takagawa, C. Watanabe, Bend formability and strength of Cu-Be-Co alloys, J. Mater. Sci. 46, 4284-4289 (2011).

[42] R. Markandeya, S. Nagarjuna, D.S. Sarma, Influence of prior cold work on age hardening of $\mathrm{Cu}-\mathrm{Ti}-\mathrm{Zr}$ alloys, Mater. Sci. Technol. 21, 1171-1180 (2005).

[43] R. Markandeya, S. Nagarjuna, D.S. Sarma, Effect of prior cold work on age hardening of $\mathrm{Cu}-3 \mathrm{Ti}-1 \mathrm{Cr}$ alloy, Mater. Charact. 57, 348-357 (2006).

[44] R. Markandeya, S. Nagarjuna, D.S. Sarma, Precipitation hardening of Cu-3Ti-1Cd alloy, J. Mater. Eng. Perform. 16, 640-646 (2007).

[45] R. Monzen, T. Terazawa, C. Watanabe, Influence of external stress on discontinuous precipitation behavior in a $\mathrm{Cu}-\mathrm{Ag}$ alloy, Metall. Mater. Trans. A 41, 1936-1941 (2010).

[46] H.P. Ng, C.J. Bettles, B.C. Muddle, Some observations on deformation-related discontinuous precipitation in an Al-14.6at.\%Zn alloy, J. Alloy. Compd. 509, 1582-1589. (2011).

[47] S. Tanaka, M. Mizusawa, H. Miura, T. Hagisawa, The influence of $\mathrm{Zr}$, P additions on microstructure and ductility of $\mathrm{Cu}-\mathrm{Ni}-\mathrm{Si}$ forged alloys, J. Jpn. Inst. Met. 78, 7-15 (2014).

[48] S. Semboshi, J. Ikeda, A. Iwase, T. Takasugi and S. Suzuki, Effect of boron doping on cellular discontinuous precipitation for age-hardenable Cu-Ti alloys, Materials 8, 3467-3478 (2015).

[49] S. Ueta, M. Hida and M. Kajihara, Effects of Fe, W and Mo on kinetics of discontinuous precipitation in the $\mathrm{NiCr}$ system, Mater. Trans. A 53, 1744-1752 (2012).

[50] S. Ueta, M. Hida And M. Kajihara, Influences of Co, Cu and V on kinetics of discontinuous precipitation in the Ni-Cr system, ISIJ Int. 53, 347-355 (2013).

[51] T.S. Gatsenko, Y.O. Lyashenko, O.A. Shmatko, Vplyv tretoho elementu na shvydkist' komirkovoho rozpadu v splavi $\mathrm{Cu}-4.35$ at.\%Ti, Visnyk Cherkaskogo Universytetu, Seriya Fizyko-Matematychni Nauky 269, 31-37 (2013).

[52] Y.O. Lyashenko, S. I. Derevyanko, O.A. Shmatko, 'Rozrakhunok vplyvu dodavannya tret'oho komponenta do systemy $\mathrm{Cu}$-Ti na enerhiyu sehrehatsiyi v protsesakh komirkovoho rozpadu, Visnyk Cherkaskogo Universytetu, Seriya Fizyko-Matematychni Nauky 309, 49-57 (2014).
[53] W.A. Soffa, D.E. Laughlin, High-strength age hardening copper-titanium alloys: redivivus, Prog. Mater. Sci. 49, 347-366 (2004).

[54] T.S. Gatsenko, Y.O Bondarenko, O.A. Shmatko, Kinetic and thermodynamic cellular precipitation parameters of $\mathrm{Cu}$-Ti solid solutions, Metallofizika i Noveishie Tekhnologii 30, 337-346 (2008).

[55] A. Heckl, S. Cenanovic, S. Neumeier, M. Goken, R.F. Singer, Reasons for the enhanced phase stability of Ru-containing nickel-based superalloys, Acta Mater. 59, 6563-6573. (2011).

[56] A. Heckl, S. Cenanovic, M. Goken, R.F. Singer, Discontinuous precipitation and phase stability in Re- and Ru-containing nickel-base superalloys, Metall. Mater. Trans. A 43, 10-19 (2012).

[57] Y. Liu, L.C. Zhang, B.S. Senturk, J.V. Mantese, S.P. Alpay, M. Aindow, Discontinuous precipitation of $\beta$-Ru phase in Ni-18Ru alloys, J Mater Sci 47, 5701-5705 (2012).

[58] S.S. Hosmani, P. Kuppusami, R.K. Goyal, in: An introduction to surface alloying of metals, nitriding of binary iron-based alloys: an overview, 29-41, SpringerBriefs in Manufacturing and Surface Engineering, Springer India 2014.

[59] H. Selg, E. Bischoff, S.R. Meka, R.E. Schacherl, T. Waldenmaier, E.J. Mittemeijer, Molybdenum-nitride precipitation in recrystallized and cold-rolled Fe-1 at. pct Mo alloy, Metall. Mater. Trans. A 44, 4059-4070 (2013).

[60] N.C.S. Srinivas, V.V. Kutumbarao, Growth mechanism for discontinuous precipitation in a multi-component (Fe-Cr-Mn-N) system, Scripta Mater. 51, 1105-1109 (2004).

[61] D. Wang, F. Ernst, H. Kahn, A.H. Heuer, Cellular precipitation at a 17-7 PH stainless steel interphase interface during low-temperature nitridation, Metall. Mater. Trans. A 45, 3578-3585 (2014).

[62] D.Q. Peng, T.H. Kim, J.H. Chung, J.K. Park, Development of nitride-layer of AISI 304 austenitic stainless steel during high-temperature ammonia gas-nitriding, Appl. Surf. Sci. 256, 7522-29 (2010).

[63] A.R. Clauss, E. Bischoff, S.S. Hosmani, R.E. Schacherl, E.J. Mittemeijer, Crystal structure and morphology of mixed $\mathrm{Cr}_{1-\mathrm{x}} \mathrm{Al}_{\mathrm{x}} \mathrm{N}$ nitride precipitates: gaseous nitriding of a Fe-1.5 wt pet $\mathrm{Cr}-1.5$ wt pet Al alloy, Metall. Mater. Trans. A 40, 1923-34 (2009).

[64] S. Jung, S.R. Meka, R.E. Schacherl, E. Bischoff, E.J. Mittemeijer, Nitride formation and excess nitrogen uptake after nitriding ferritic Fe-Ti-Cr alloys, Metall. Mater. Trans. A 43, 934-44 (2012).

[65] C.W. Kang, Sai Ramudu Meka, R.E. Schacherl, E.J. Mittemeijer, Microstructure and kinetics of nitride precipitation in a quaternary iron-based model Fe-2.82 at. Pct Cr-0.13 at. pct Mo-0.18 at. pct V, Alloy Metall. Mater. Trans. A 46, 238-336 (2015). 